\title{
Supplementary Information: Supramolecular Mechanism of Viral Envelope Disruption by Molecular Tweezers
}

Tatjana Weil ${ }^{1 \#}$, Rüdiger Groß ${ }^{1 \#}$, Annika Röcker ${ }^{1 \#}$, Kenny Bravo-Rodriguez ${ }^{2 \#}$, Christian Heid ${ }^{3}$, Andrea Sowislok ${ }^{3}$, My-Hue Le ${ }^{3}$, Nelli Erwin ${ }^{4}$, Mridula Dwivedi ${ }^{4}$, Stephen M. Bart ${ }^{5,6}$, Paul Bates $^{5,6}$, Lukas Wettstein ${ }^{1}$, Janis A. Müller ${ }^{1}$, Mirja Harms ${ }^{1}$, Konstantin Sparrer ${ }^{1}$, Yasser B. Ruiz-Blanco, ${ }^{2}$ Christina M. Stürzel $^{1}$, Jens von Einem ${ }^{7}$, Sina Lippold ${ }^{7}$, Clarissa Read ${ }^{7,8}$, Paul Walther $^{8}$, Marco Hebel ${ }^{9,10}$, Florian Kreppel ${ }^{11}$, Frank-Gerrit Klärner ${ }^{3}$, Gal Bitan ${ }^{12}$, Michael Ehrmann $^{13}$, Tanja Weil ${ }^{9,10}$, Roland Winter ${ }^{4}$, Thomas Schrader ${ }^{3 *}$, James Shorter ${ }^{6,14 *}$, Elsa Sanchez-Garcia ${ }^{2 *}$ and Jan Münch ${ }^{1 *}$

${ }^{1}$ Institute of Molecular Virology, Ulm University Medical Center, 89081 Ulm, Germany;

${ }^{2}$ Computational Biochemistry, Center of Medical Biotechnology, University of DuisburgEssen, 45117 Essen, Germany;

${ }^{3}$ Faculty of Chemistry, University of Duisburg-Essen, 45117 Essen, Germany;

${ }^{4}$ Physical Chemistry I-Biophysical Chemistry, Faculty of Chemistry and Chemical Biology, TU Dortmund University, 44227 Dortmund, Germany;

${ }^{5}$ Department of Microbiology, Perelman School of Medicine at the University of Pennsylvania, Philadelphia, Pennsylvania 19104, U.S.A.;

${ }^{6}$ Cell and Molecular Biology Graduate Group, Perelman School of Medicine at the University of Pennsylvania, Philadelphia, Pennsylvania 19104, U.S.A.;

${ }^{7}$ Institute of Virology, Ulm University Medical Center, 89081 Ulm, Germany;

${ }^{8}$ Central Facility for Electron Microscopy, Ulm University, 89081 Ulm, Germany;

${ }^{9}$ Max Planck Institute for Polymer Research, 55128 Mainz, Germany;

${ }^{10}$ Institute of Inorganic Chemistry I, Ulm University, 89081 Ulm, Germany;

${ }^{11}$ Center for Biomedical Education and Research, University of Witten/Herdecke, 58453 Witten, Germany;

${ }^{12}$ Department of Neurology, David Geffen School of Medicine, Brain Research Institute, and Molecular Biology Institute, University of California, Los Angeles, California 90095, U.S.A.; ${ }^{13}$ Microbiology II, Center of Medical Biotechnology, University of Duisburg-Essen, 45117 Essen, Germany;

${ }^{14}$ Department of Biochemistry and Biophysics, Perelman School of Medicine at the University of Pennsylvania, Philadelphia, Pennsylvania 19104, U.S.A.

\# equal contribution

*For correspondence:

jan.muench@uni-ulm.de; elsa.sanchez-garcia@uni-due.de; jshorter@pennmedicine.upenn.edu; thomas.schrader@uni-due.de; 


\section{Table of Contents}

1. Material and Methods $\quad$ S3

2. Supplementary Figures $\quad \mathrm{S} 12$

3. Supplementary Tables $\quad$ S29

4. References $\quad$ S35 


\section{Materials and Methods}

\section{Computational details}

Free energy perturbation (FEP) ${ }^{1}$ and extended-system Adaptive Biasing Force ${ }^{2}$ (eABF) calculations were used to study the binding of CLR05 to PAP248-286. The FEP included the alchemical transformation of CLR01 to CLR05 while forming an inclusion complex with Lys/Arg residues in PAP248-286 to evaluate the relative binding affinity of CLR05 with respect to CLR01. Molecular dynamics (MD) simulations of the only-DOPC and mixed (54:30:36 DOPC:PSM:Chol) bilayers in the presence of nine ligand molecules (CLR01, CLR05 or PC) were performed in explicit water with the tweezers and clip molecules initially placed $4 \AA$ over the membrane. Three independent replicas of $110 \mathrm{~ns}$ each were performed for all systems where the first $10 \mathrm{~ns}$ were not considered in the analysis of the results. The insertion of CLR01/CLR05/PC into the bilayers was studied using the eABF scheme. ${ }^{2}$ These calculations were done with NAMD2. $9^{3}$ and the CHARMM36 force field ${ }^{4}$. The parameters for CLR01/CLR05/PC were obtained using the Swissparam server ${ }^{5}$ and validated by us. The total simulated time reported in this study was above $7.7 \mu$ s.

\section{REMD simulation of the interaction between PAP248-286 and CLR05}

The interactions of $\mathrm{PAP}_{248-286}$ with the molecular tweezer CLR05 were investigated using Replica Exchange Molecular Dynamics (REMD) simulations ${ }^{6,7}$ performed with Gromacs $4.6^{8}$ and the CHARMM27 force field (FF) ${ }^{9,10}$. In total, 37 replicas were simulated during $75 \mathrm{ns,}$ following a setup analogous to the previously reported for $\mathbf{C L R O 1}^{11}$.

\section{Free Energy calculations of PAP248-286 with tweezers}

The interactions of PAP $248-286$ with the molecular tweezers CLR01 and CLR05 were also investigated using free energy calculations. The NAMD2.9 code $^{3}$ was used with the CHARMM22 force field (including CMAP corrections) ${ }^{10,12}$ and the TIP3P model for water ${ }^{13}$. The parameters for CLR01 and CLR05 were obtained using the Swissparam server ${ }^{5}$ and have been previously validated by us ${ }^{14,15}$. The initial coordinates of PAP $_{248-286}$ were taken from the Protein Data Bank, code $2 \mathrm{~L} 3 \mathrm{H}^{16}$. For each Lys and Arg (except Lys272, which is only accessible in certain conformations) the relative free energy change for the binding of CLR01 and CLR05 was calculated considering inclusion complexes with a 1:1 ratio of $\mathrm{PAP}_{248-286}$ and molecular tweezers. The alchemical transformation was performed using NAMD2. $9^{3}$ and Free Energy Perturbation theory ${ }^{1}$ (FEP). Only the substituents in the tweezers were alchemically transformed. The temperature was set to $300 \mathrm{~K}$. The alchemical transformation was accomplished using 60 windows. In each window, $4 \cdot 10^{5}$ time steps of MD simulation (including $1 \cdot 10^{5}$ time steps of equilibration) were performed to generate a representative ensemble. The forward and backward transformations were performed to estimate the error in the free energy values using the Bennett acceptance ratio estimator ${ }^{17}$.

In addition, the extended-system Adaptive Biasing Force $(\mathrm{eABF})^{18}$, as implemented in NAMD2.9, was used to estimate if the tweezers form an inclusion complex with each of the seven considered residues. Two collective variables were selected (Fig. S1b). The collective 
variable representing the distance between the included amino acid and the tweezers was explored from $0 \AA$ to $12 \AA$ with a $0.5 \AA$ width, while the angle measuring the degree of inclusion of the amino acid in the cavity of the tweezers was explored from $0^{\circ}$ to $180^{\circ}$ with a $10^{\circ}$ width. In the inclusion complex, the optimal values of the collective variables are approximately 0.25 $\AA$ and $90^{\circ}$. For each bin, 100 samples were taken before the application of the biasing force. The timestep of the simulations was set to $1 \mathrm{fs}$ and the total simulated time was $100 \mathrm{~ns}$. The temperature was set to $300 \mathrm{~K}$.

\section{Molecular dynamics simulations of the ligands in model membranes}

Two model lipid bilayers were used for the study of the interaction of CLR01, CLR05 and PC with membranes. We built a DOPC bilayer containing 120 DOPC lipids per leaflet and a mixed bilayer containing 54, 30 and 36 molecules per leaflet of DOPC, SM and CHL, respectively. Both bilayers were built using the CHARMM-GUI interface. ${ }^{19,20}$

The interaction of each molecule with the model membranes was studied using three independent molecular dynamics (MD) simulations containing nine molecules of CLR01, CLR05 or PC. The molecules were initially placed $4 \AA$ over the membrane. The membrane was oriented perpendicular to the z-axis and the center of mass of the nitrogen atoms in both leaflets was harmonically restrained to the coordinates' origin to prevent the membrane drifting along the z-axis. A harmonic potential was used to prevent CLR01, CLR05 or PC to cross the boundary of the simulated cell in the $+z$ direction.

MD simulations were performed with the NAMD2.9 program using the CHARMM36 force field. ${ }^{3,4}$ The systems were solvated using the TIP3P water model and ions added to reach $0.1 \mathrm{M}$ concentration. ${ }^{13}$ A timestep of $2 \mathrm{fs}$ was used. The temperature was set to $300 \mathrm{~K}$. Before the production runs, the bilayers were equilibrated for $50 \mathrm{~ns}$. In all cases, $110 \mathrm{~ns}$ of production MD were performed, and the initial $10 \mathrm{~ns}$ were discarded. The total MD simulated time was nearly $1 \mu$ s for each ligand.

\section{Free energy calculations of CLR01/CLRO5/PC in bilayers}

The PMF profiles for the insertion of CLR01, CLR05 and PC in the bilayers were calculated using the eABF method ${ }^{18}$. The $\mathrm{z}$ projection of the center of mass of the tweezers was taken as the collective variable. The collective variable was divided in 22 windows of $2 \AA$ widths. Each window was simulated for $10 \mathrm{~ns}$. In each bin, 200 samples were collected before starting to apply the biasing force. The initial geometry for each window was taken from a Steered Molecular Dynamic (SMD) simulation ${ }^{21,22}$ in which a force in the $-\mathrm{z}$ direction was applied to CLR01 to accelerate the insertion of CLR01 in the membrane. The SMD was performed under the same conditions as described for the standard MD simulations. In addition, a constant velocity regime was used with a speed of $0.0005 \AA$ timestep $^{-1}$ and a force constant of $7 \mathrm{kcal}$ $\mathrm{mol}^{-1} \AA^{-1}$.

\section{$Q M / M M$ calculations}

The inclusion complexes of CLR01 with DOPC and SM were studied using QM/MM optimizations. To this end, randomly selected snapshots from the MD simulations of CLR01 with or without the mixed bilayer in explicit water were optimized at the B3LYP-D3/def2- 
SVP//CHARMM36 $6^{4,23-25}$ level of theory using ChemShell v3.5. ${ }^{26}$ For each complex, five snapshots were selected. An electrostatic embedding scheme ${ }^{27}$ was employed together with a charge shift scheme. ${ }^{28,29}$ The active region consisted of a $20 \AA$ region around CLR01 and the lipid forming the inclusion complex. The tweezer together with the trimethylammonium part of the lipid head were chosen as the QM region, which was calculated with Turbomole v6. $6^{24}$ while DL_POLY ${ }^{30}$ was used for the MM region. All atoms within the active region were allowed to freely move in each optimization step.

\section{Small molecules, peptides and seminal amyloids}

CLR01, CLR05 and PC were prepared as described previously ${ }^{15,31-33}$ and 1.3-7.4 mM stock solutions were prepared in PBS (for CLR01 and PC) or diluted $\mathrm{NaOH} /$ water/10 mM NaH $2 \mathrm{PO}_{4}$ $\mathrm{pH}=7.6$ (for CLR05). Synthetic peptides PAP248-286, PAP85-120, and SEM1(45-107) were purchased from Keck Biotechnology Resource Laboratory, Shanghai Hanhong Chemical Company or Celtek peptides. For fibril formation, peptides were reconstituted and assembled as previously described ${ }^{34-36}$.

\section{Amyloid detection assay}

For assembly experiments, reconstituted peptides PAP248-286 (1 mM), PAP85-120 (1 mM) ore SEM1 (45-107) (0.5 mM) were incubated with CLR01, CLR05 or PC and agitated at $37^{\circ} \mathrm{C}$ at $1400 \mathrm{rpm}$. At various time points, aliquots $(1 \mu \mathrm{l})$ were removed and added to $25 \mu \mathrm{M}$ ThT in PBS (200 $\mu$ l). Changes in fluorescence (excitation: $440 \mathrm{~nm}$, emission: $482 \mathrm{~nm}$ ) were measured using a Tecan Safire2 microplate reader. Alternatively, reactions were processed for TEM as described $^{11}$.

For amyloid-remodeling experiments, fibrils $(20 \mu \mathrm{M}$, based on peptide monomer concentrations) were diluted into an assay buffer (25 mM HEPES, $150 \mathrm{mM} \mathrm{KOAc,} 10 \mathrm{mM}$ $\left.\mathrm{Mg}(\mathrm{OAc})_{2}, \mathrm{pH} 7.4\right)$ in the presence of ATP $(5 \mathrm{mM})$ and incubated with either CLR01, CLR05 or PC. After $2 \mathrm{~h}$, aliquots $(5 \mu \mathrm{l})$ were removed and added to $25 \mu \mathrm{M}$ ThT in PBS (55 $\mu \mathrm{l})$ before ThT fluorescence was measured. Alternatively, reactions were processed for TEM as described ${ }^{11}$.

\section{Confocal microscopy}

Fibrils $(200 \mu \mathrm{g} / \mathrm{ml}$ in PBS) were stained with Proteostat Amyloid Plaque Detection Kit (Enzo Life Sciences, Plymouth Meeting, PA). Then, fibrils were treated with a 20-fold excess CLR01, CLR05 or PC and mixed 1:2 with MLV-Gag-YFP virions. Samples were transferred to $\mu$-slides VI0.4 (Ibidi, Munich, Germany) and imaged with a Zeiss LSM confocal microscope.

\section{Effect of tweezer on HIV infection and amyloid-mediated enhancement}

The reporter cell line TZM-bl was obtained through the NIH ARRRP and cultured as described ${ }^{11}$. Virus stocks of the R5-tropic HIV-1 NL4-3 92TH014 derivative were generated by transient transfection of $293 \mathrm{~T}$ cells as described ${ }^{35}$. Stocks were analyzed by p24 antigen ELISA and stored at $-80^{\circ} \mathrm{C}$. To compare the antiviral effects of CLR05 and PC to CLR01, 3fold dilution series of the compounds were prepared before R5-tropic HIV-1 NL4-3 92TH014 was added (20 ng/ml p24 antigen), resulting in CLR01/CLR05/PC concentrations of 0-150 $\mu \mathrm{M}$. After incubation for $10 \mathrm{~min}$ at $37^{\circ} \mathrm{C}$, the mixtures were resuspended and added to $10^{4}$ 
TZM-bl cells in $180 \mu 1$ medium seeded in 96-well flat-bottom plates the day before infection. Infection rates were determined 3 days post infection by detecting $\beta$-galactosidase activity in cellular lysates using the Tropix Gal-Screen kit (Applied Biosystems) and the Orion microplate luminometer (Berthold). All values represent reporter gene activities (relative light units per second; RLU/s) derived from triplicate infections minus background activities derived from uninfected cells. To assess the effect of CLR01, CLR05 and PC on amyloid-mediated enhancement of HIV-1 infection, $200 \mu \mathrm{g} / \mathrm{ml}$ fibrils (44 $\mu \mathrm{M}$ SEVI, $45 \mu \mathrm{M}$ PAP85-120 fibrils, $28 \mu \mathrm{M}$ SEM1(45-107) fibrils) were treated with a 20-fold molar excess of CLR05 or CLR01 for $10 \mathrm{~min}$ at room temperature. The mixtures were serially diluted 5-fold before R5-tropic HIV-1 NL4-3 92TH014 was added (1 ng/ml p24 antigen). After $5 \mathrm{~min}, 20 \mu \mathrm{l}$ of these mixtures were added to $10^{4} \mathrm{TZM}-\mathrm{bl}$ cells and infection rates were determined 3 days post infection.

\section{Giant unilamellar vesicles}

Giant unilamellar vesicles (GUVs) were prepared by electroformation on optically transparent and electrically conductive indium tin oxide (ITO)-coated glass slides in a preparation chamber consisting of a closed bath imaging chamber RC-21B affixed to a P-2 platform topped with a flow-through temperature block. A solution of pure DOPC (1,2-dioleoyl-sn-glycero-3phosphocholine) containing $0.2 \mathrm{~mol} \% \mathrm{~N}-\mathrm{Rh}$-DHPE (N-(lissamine rhodamine B sulfonyl)-1,2dihexadecanoyl-sn-glycero-3-phosphoethanolamine) or a lipid mixture of $45 \mathrm{~mol} \% \mathrm{DOPC}, 25$ mol\% sphingomyelin (SM), and $30 \mathrm{~mol} \%$ cholesterol (Chol) containing $0.2 \mathrm{~mol} \% \mathrm{~N}-\mathrm{Rh}-\mathrm{DHPE}$ and $0.1 \mathrm{~mol} \%$ Bodipy-Chol (23-(dipyrrometheneboron difluoride)-24-norcholesterol) in chloroform was spread on an ITO-coated cover slip $(20 \mu \mathrm{L}, 1 \mathrm{mg} / \mathrm{mL})$, spin-coated at $800 \mathrm{rpm}$ for $1 \mathrm{~min}$, and subsequently dried under vacuum for at least $2 \mathrm{~h}$. Then, the lipids were hydrated in $10 \mathrm{mM} \mathrm{NaH} 2 \mathrm{PO} 4$ buffer ( $\mathrm{pH}$ 7.6) containing the water-soluble fluorophore ATTO 647 (5 $\mu \mathrm{M})$ within the preparation chamber. The electroformation of pure DOPC and the $\mathrm{DOPC} / \mathrm{SM} / \mathrm{Chol}$ mixture was performed at $\mathrm{RT}$ and $60^{\circ} \mathrm{C}$, respectively, by applying a frequency-alternating current field $(500 \mathrm{~Hz}, 100 \mathrm{mV}$ for $10 \mathrm{~min}, 1 \mathrm{~V}$ for $20 \mathrm{~min}$, and $1.6 \mathrm{~V}$ for $2.5 \mathrm{~h}$ ) to the ITO electrodes by a TG315 function generator. The preparation chamber was cooled down to RT in case of the lipid mixture and carefully rinsed with $10 \mathrm{mM} \mathrm{NaH} \mathrm{PO}_{4}$ buffer to remove the water-soluble ATTO 647 that was not enclosed in the interior of the vesicles. $150 \mu \mathrm{M}$ CLR05 or PC dissolved in $10 \mathrm{mM} \mathrm{NaH}_{2} \mathrm{PO}_{4}$ buffer were added to the samples and imaged after different incubation times using a Biorad confocal microscope coupled via a side port to an inverted Nikon microscope enabling fluorescence excitation in the focal plane of a Nikon objective. Fluorescence of Bodipy-Chol, N-Rh-DHPE, and ATTO 647 was acquired using a $\mathrm{Kr} / \mathrm{Ar}$ laser. Analysis of the data was performed using the Fiji software.

\section{Liposome dye leakage}

Liposomes for dye-leakage assay were prepared by thin-film hydration \& extrusion. DOPC (1,2-dioleoyl-sn-glycero-3-phosphocholine), sphingomyelin (Egg SM) and cholesterol (ovine wool) dissolved in chloroform (Avanti Polar Lipids, Alabaster, USA) were mixed at 45/25/30 $\mathrm{mol} \%$ ratio in a glass round-bottom flask. The solvent was then evaporated by slowly applying a vacuum at a Schlenk line. The vacuum was held for $2 \mathrm{~h}$ and then purged with argon. The lipid film was then hydrated by adding $50 \mathrm{mM} \mathrm{5(6)-carboxyfluorescein} \mathrm{prepared} \mathrm{in} \mathrm{50 \%} \mathrm{PBS}$ (resulting in a solution isoosmolar to PBS) and adjusted to $\mathrm{pH} 7.4$ with $\mathrm{NaOH}$, yielding a total lipid concentration of $5 \mathrm{mM}$. The flasks were shaken at $60^{\circ} \mathrm{C}, 180 \mathrm{rpm}$, for $1 \mathrm{~h}$. Small 
unilamellar vesicles were then prepared by $25 \mathrm{x}$ extrusion through $0.2 \mu \mathrm{M}$ polycarbonate membranes (Nuclepore Track-Etched Membrane, Whatman, Maidstone, USA) in a Mini Extruder (Avanti Polar Lipids) on a heating platform at $60^{\circ} \mathrm{C}$. Free dye was removed by $2 \mathrm{x}$ size-exclusion filtration using PD midiTrap Sephadex G-25 columns (GE Healthcare, Buckinghamshire, UK) and liposomes then quantified by nanoparticle tracking analysis (NTA) using a ZetaView (ParticleMetrix, Inning, Germany). For assay in 96-well format, liposome preparations were diluted in PBS and $2.25^{*} 10^{\wedge}$ //well added to plates in $90 \mu$ l volume. Fluorescence intensity was read in a Cytation 3 plate reader (Biotek, Winooski, USA). Baseline was established by measuring fluorescence for $5 \mathrm{~min}, 10 \mu \mathrm{l}$ of compounds then added and plates incubated for 30 min more with measurements every $1 \mathrm{~min}$. Maximum intensity $(100 \%$ dye release) was then measured by adding Triton X-100 to $1 \%$ final concentration and again measuring for $5 \mathrm{~min}$.

\section{Atomic force microscopy}

Stock solutions $(10 \mathrm{mg} / \mathrm{mL})$ of every single lipid in chloroform were mixed to obtain the desired composition and amount. After most of the solvent was removed with a nitrogen steam, remaining chloroform was evaporated under vacuum for at least $2 \mathrm{~h}$. The dried lipid mixture was hydrated with $20 \mathrm{mM}$ Tris (pH 7.4) and $5 \mathrm{mM} \mathrm{MgCl}_{2}$. After extensive vortexing and sonification in a water bath at a temperature above the melting temperature of the respective lipid mixture and applying five freeze-thaw cycles, large unilamellar vesicles with a pore size of $100 \mathrm{~nm}$ size were obtained by extrusion trough a polycarbonate membrane (Avanti Polar Lipids, Alabaster USA). Vesicle fusion on mica was carried out by depositing $70 \mu \mathrm{L}$ of the large unilamellar vesicles solution on freshly cleaved mica and incubation in a wet chamber at $70{ }^{\circ} \mathrm{C}$ for $2 \mathrm{~h}$. After vesicle fusion, the samples were rinsed carefully with Tris buffer to remove unspread vesicles. For the tweezer-membrane interaction studies, $200 \mu \mathrm{L}$ of the tweezer (at the desired concentrations) were injected into the AFM fluid cell. Measurements were performed on a MultiMode scanning probe microscope with a Nano- Scope IIIa controller (Digital Instruments, Santa Barbara, CA) and use of a J-Scanner (scan size $125 \mu \mathrm{m}$ ). Images were obtained by applying the tapping mode in liquid with oxide-sharpened silicon nitride (DNP-S) or sharp nitride lever (SNL) probes mounted in a fluid cell (MTFML, Veeco (now Bruker), Karlsruhe, Germany). Tips with nominal force constants of $0.24 \mathrm{Nm}^{-1}$ were used at driving frequencies around $9 \mathrm{kHz}$ and drive amplitudes between 200 and $800 \mathrm{mV}$. Scan frequencies were between 1.0 and $1.94 \mathrm{~Hz}$. Height and phase images of sample regions were acquired with resolutions of $512 \times 512$ pixels. All measurements were carried out at room temperature and analyzed by using the analysis and processing software NanoScope version 5 and Origin 9.1 (OriginLab Corporation, Northampton, MA, USA).

\section{Cryo-TEM}

For cryo-TEM of HCMV extracellular virions, $1.5 \mathrm{ml}$ cell-free supernatant of HCMV infected cells virions was centrifuged at 14,000 rpm for $30 \mathrm{~min}$. Pelleted virions were resuspended in 20 $\mu 1$ serum-free medium and subsequently treated with serum-free medium or $50 \mu \mathrm{M}$ CLR01 for $30 \mathrm{~min}$ at $37^{\circ} \mathrm{C}$. Then, $3.5 \mu \mathrm{l}$ of the virus preparations were applied to a freshly glow-discharged C-flat holey carbon grid (CF-2/2-4C, Protochips) and then vitrified in liquid ethane by a Vitrobot type FP 5350/60 (FEI). Images with a pixel size of $0.187 \mathrm{~nm}$ were acquired using the 
JEM2100F (Jeol) microscope at an acceleration voltage of $200 \mathrm{kV}$. For this, a direct electron camera type DE12 (Direct Electron) and the SerialEM software version 3.5.3 were used.

\section{Comparative NMR studies}

1:1 complexes and 3:1 complexes between CLR01, CLR05 and PC and the lipids DOPC and SM were prepared in deuterated methanol $\left(\mathrm{CD}_{3} \mathrm{OD}\right)$ for homogeneous solubility at $0.33 \mathrm{mM}$ lipid concentration and $0.33 \mathrm{mM}$ as well as $1.00 \mathrm{mM}$ host concentration. Chemical shift changes to higher field for the $\mathrm{NMe}_{3}$ signals of the choline head-group were monitored as quantitative relative indicators for their potential inclusion inside the host cavities. $\mathrm{T}=298 \mathrm{~K}$.

\section{NMR Titrations}

A lipid guest solution $(\mathrm{c}=0.33 \mathrm{mmol} / \mathrm{L})$ was prepared in deuterated methanol $\mathrm{CD}_{3} \mathrm{OD} .600 \mu \mathrm{L}$ of this solution were placed in an NMR tube and a spectrum was recorded. The CLR01 host solution $(\mathrm{c}=10 \mathrm{mmol} / \mathrm{L})$ was prepared using the guest solution to keep the guest concentration constant during the titration. Increasing amounts of host solution were added and the resulting NMR spectra were recorded. The resulting CLR01 concentrations were: $0.16 \mathrm{mM}, 0.32 \mathrm{mM}$, $0.48 \mathrm{mM}, 0.62 \mathrm{mM}, 0.91 \mathrm{mM}, 1.18 \mathrm{mM}, 1.43 \mathrm{mM}, 1.89 \mathrm{mM}, 2.31 \mathrm{mM}, 2.85 \mathrm{mM}, 3.33 \mathrm{mM}$. Hence the final host guest ratio was higher than 10:1. For the determination of binding constants, the chemical shift changes of the $\mathrm{N}(\mathbf{M e})_{3}$, the $\mathrm{P}-\mathrm{O}-\mathbf{C H}_{2}-\mathrm{CH}_{2}$ and the $\mathrm{P}-\mathrm{O}-\mathrm{CH}_{2}-\mathbf{C H}_{2}$ protons were monitored during the titration. From the resulting binding isotherms, 1:1 affinities and $\Delta \delta_{\max }$ values between $1.06 \mathrm{ppm}$ and $4.36 \mathrm{ppm}$ were calculated by non-linear regression. NMR titrations were performed for CLR01, CLR05 and PC with both lipids DOPC and SM.

\section{Cell viability}

The effect of CLR05 on the metabolic activity of TZM-bl cells was analyzed using CellTiterGlo assay (Promega). After 3 days of incubation, supernatant was discarded and $50 \mu 1$ PBS and $50 \mu \mathrm{l}$ CellTiter-Glo Reagent were added to the cells. After incubation and gentle shaking for ten minutes at room temperature, luminescence in the cell-free supernatant was determined via the Orion microplate luminometer (Berthold). The luminescence signal is proportional to the amount of ATP and thus, the number of viable cells present.

\section{p24 release assay}

HIV-1 NL4-3 92TH014 was incubated for $10 \mathrm{~min}$ at $37^{\circ} \mathrm{C}$ with buffer, or $100 \mu \mathrm{M}$ CLR01, CLR05 or PC before the mixtures were centrifuged at $20,000 \times \mathrm{g}$ and $4{ }^{\circ} \mathrm{C}$ for $1 \mathrm{~h}$. The p24 content of the supernatant and pellet was determined using an in house p24-antigen ELISA.

\section{RNA release assay}

ZIKV MR766 (8.89x107 TCID50/ml) was purified via sucrose cushion spin. To this end, 500 $\mu \mathrm{l}$ virus stock were added on top of a $200 \mu 120 \%$ sucrose solution and centrifuged for $2 \mathrm{~h}$ at $20,000 \times \mathrm{g}$. After discarding the supernatant, the virus pellet was resuspended in $100 \mu \mathrm{l}$ PBS, resulting in a 5-fold concentration of viral particles. For the preparation of controls, the supernatant of uninfected Vero E6 cells was treated equally. Purified virus or cell supernatant were then incubated with PBS, 1.5-150 $\mu$ M CLR01, PC, $150 \mu \mathrm{M}$ Triton X-100 or 15-300 $\mu \mathrm{M}$ CLR05 for $30 \mathrm{~min}$ at $37^{\circ} \mathrm{C}$. Then, the samples were UV-inactivated for $1 \mathrm{~h} .10 \mu \mathrm{l}$ of each sample were used to quantify the RNA concentration using a QuantiFluor ${ }^{\circledR}$ RNA System and 
a Quantus Fluorometer (Promega) according to the manufacturer's instructions. From each sample, the signal of PBS treated ZIKV was subtracted to obtain the actually released RNA concentrations.

\section{Aggregation of virus-like particles (VLPs)}

Virus-like-particles of murine leukemia virus tagged with YFP (MLVgag-YFP VLPs) were produced by transfection of HEK293T cells with pcDNA3_MLV Gag-YFP using Transit LT1 (Mirus). 2 days post-transfection, supernatants were harvested, clarified by centrifugation, aliquoted and frozen at $-80^{\circ} \mathrm{C}$ until use. Thawed supernatants were diluted in PBS and analyzed by fluorescent nanoparticle tracking analysis (F-NTA) using a ZetaView TWIN (Particle Metrix). To study aggregation of VLPs, pre-diluted VLPs were incubated with compounds (or PBS only) for 30 or $120 \mathrm{~min}$ at room temperature and then injected into the ZetaView. Particles were then tracked using the following settings: $25^{\circ} \mathrm{C}$ fixed temperature, $488 \mathrm{~nm}$ excitation laser, $500 \mathrm{~nm}$ fluorescence filter, 11 positions, $2 \mathrm{~s} /$ video per position, sensitivity 95 , shutter 250,15 fps, 3 acquisitions with $20 \mu$ PBS pumped between measurements. Tracked particle size distributions were analyzed in FlowJo 10.7.1 and gated to reveal free VLPs based on the tracking data of untreated particles. The number of free particles was averaged per tracked position. Note that in fluorescence mode, only VLPs but no fibrils/other macromolecules are visualized and tracked. Aggregation is inferred from apparent size changes due to reduced diffusion speed of particles.

\section{Antiviral assays}

Herpes simplex virus 1 (HSV-1) and HSV-2: Dilution series of CLR01, CLR05 and PC were prepared in serum free minimal essential medium (MEM, Invitrogen, Germany). HSV-1 (strain $\mathrm{R}$ 10.2) was added corresponding to infection rates of about $50 \%$, resulting in final compound concentrations of $0-150 \mu \mathrm{M}$. After incubation for $30 \mathrm{~min}$ at $37^{\circ} \mathrm{C}$, mixtures were added to $1.7 \times 10^{4}$ Vero E6 cells per well in a 96-well flat-bottom plate and incubated for $1 \mathrm{~h}$ at $37^{\circ} \mathrm{C}$. Then, media were changed, and cells were overlayed with $0.6 \%$ methylcellulose. 12 hours post infection (hpi) cells were fixed and infection rates were determined by indirect immunofluorescence staining for HSV-1 infected cell protein 0 (ICP0) antigen.

Human Adenovirus type 5 (HAdV5): The E1-deleted replication-deficient human adenovirus type 5-based vector containing a HCMV promoter-controlled EGFP expression cassette was produced, purified and characterized as described ${ }^{11}$. To assess effects of CLR01 and CLR05 on HAdV 5 infectivity, the vector was titrated with 0-100 $\mu$ M CLR01 or CLR05 and incubated $10 \mathrm{~min}$ at $37^{\circ} \mathrm{C}$ in $50 \mathrm{mM}$ HEPES, $150 \mathrm{mM} \mathrm{NaCl}$, pH 7.17. $1 \times 10^{5}$ A549 cells per well were seeded 1 day prior to infection in 24-well plates and infected with $200 \mathrm{MOI}$ of the pretreated virus. EGFP expression was analyzed 1 day post transduction using a Beckman-Coulter Gallios flow cytometer.

Zika virus (ZIKV): Virus stocks of ZIKV strain MR766 (kindly provided by J. SchmidtChanasit, Bernhard Nocht Institute for Tropical Medicine, Hamburg) was propagated as described previously ${ }^{11,37}$ in Vero E6 cells (Cercopithecus aethiops derived epithelial kidney, also kindly provided by J. Schmidt-Chanasit). Virus titers were determined via the ReedMuench method ${ }^{38}$ and stored at $-80^{\circ} \mathrm{C}$. To investigate the effect of CLR01 and CLR05 on 
ZIKV infection, ZIKV MR766 at an MOI of 0.2 was incubated for $30 \mathrm{~min}$ at $37^{\circ} \mathrm{C}$ with buffer or 0.2-150 $\mu$ M CLR01, CLR05 or PC. Then, these mixtures were added to $6 \times 10^{3}$ Vero E6 cells seeded the day before into 96-well plates. After 2 days, a cell-based ZIKV immunodetection assay was performed as described ${ }^{39,40}$.

Pseudotyped lentiviral particles: Lentiviral pseudotypes harboring glycoproteins from Ebola, Marburg, SARS and Rabies virus were obtained as described previously ${ }^{39,40}$. Viral pseudotypes were incubated with CLR05 or PC for $10 \mathrm{~min}$ at $37^{\circ} \mathrm{C}$ and used to infect $10^{4} \mathrm{Huh}-7$ cells. After 3 days, infection rates were determined by quantifying firefly luciferase activity using the Luciferase Assay System (Promega, Madison, USA). All values represent reporter gene activities (relative light units per second; RLU/s) derived from triplicate infections minus background activities derived from uninfected cells.

Lentiviral-SARS-COV-2 pseudoparticle: For pseudoparticle generation 3x106 HEK293T cells were seeded in $10 \mathrm{~cm}$ dishes one day prior to transfection. The next day medium was changed, and cells were transfected with TransIT-LT1 (Mirus Bio) according to the manufacturer's instructions. A total DNA amount of $30 \mu \mathrm{g}$ DNA was transfected comprising $2 \%$ pCG1-SARS-2-S (encoding the SARS-CoV-2 Wuhan Hu-1 Spike protein, kindly provided by Stefan Pöhlmann) as well as pSEW-luc2 (encoding a firefly luciferase gene) and pCMVdR8.91 (encoding an env deficient lentiviral backbone) at a 1:1 ratio. At $8 \mathrm{~h}$ post transfection, medium was replaced with DMEM supplemented with $2.5 \%$ FCS. At 48 h post transfection, the virus stock was harvested and clarified by centrifugation ( $5 \mathrm{~min}, 1500 \mathrm{rpm})$ and virus containing supernatants were stored at $4{ }^{\circ} \mathrm{C}$.

For inhibition assay of the tweezer, lentiviral-SARS-COV-2pp were incubated for 30 minutes at $37^{\circ} \mathrm{C}$ with $150 \mu \mathrm{M}-1.17 \mu \mathrm{M}$ CLR01, CLR05, CLR03 and PC. Afterwards the tweezerpseudoparticle mixture was added on $\mathrm{CaCo} 2$ cells in 96 well plate. At $48 \mathrm{~h}$ post transduction, the infection rates were assessed by measuring firefly luciferase activity using Firefly luciferase assay kit from Promega. Therefore, supernatant was removed, and cells were washed once with PBS. PBS was discarded and cells were lysed with $40 \mu 1$ lysis-buffer per well. $30 \mu \mathrm{l}$ of these lysates were transferred to a 96-well Nunclon-delta white microwell plate and mixed with $50 \mu 1$ of Luciferase Assay substrate. Values represent \% luciferase activities (relative light units per second; RLU/s) derived from triplicate infections and normalized to values obtained for transduced cells in absence of tweezer.

Encephalomyocarditis virus (EMCV): Murine encephalomyocarditis virus (EMC strain) was obtained from ATCC and propagated in Vero E6 cells ${ }^{41}$. The virus was incubated for $30 \mathrm{~min}$ at $37^{\circ} \mathrm{C}$ either with buffer or $0.2-150 \mu \mathrm{M}$ CLR01, CLR05 or PC before adding it to $2 \times 10^{4} \mathrm{HFF}$ cells in 96-well plates (MOI 0.1). $48 \mathrm{~h}$ post infection the cytopathic effect was quantified using the 3-[4,5-dimethyl-2-thiazolyl]-2,5-diphenyl-2H-tetrazolium bromide-(MTT)-based cell viability assay ${ }^{37}$. To determine infection rates, sample values were subtracted from untreated controls that were set to $100 \%$ viability.

Influenza virus (IAV): Influenza strain A/PR/8/34 (H1N1; PR8) was purchased from ATCC and propagated in MDCK cells as previously reported ${ }^{41}$. For inhibition assays, virus was diluted 
in serum-free medium supplemented with $1 \mu \mathrm{g} / \mathrm{mL}$ TPCK treated trypsin (Sigma) and was incubated with 0-150 $\mu \mathrm{M}$ CLR01, CLR05 or PC for $30 \mathrm{~min}$ at $37^{\circ} \mathrm{C}$ before the mixtures were used to infect $2 \times 10^{4} \mathrm{~A} 549$ cells (MOI 0.2). After $1 \mathrm{~h}$ incubation at $37^{\circ} \mathrm{C}$, cells were washed three times with PBS before $100 \mu \mathrm{l}$ fresh growth medium containing $0.1 \%$ FCS and TPCK treated trypsin were added. After 48 hours, infectivity rates were determined by measuring neuramidase activity in cellular lysates (MUNANA assay). Therefore, cells were lysed for 30 min in 10\% Triton-X100 and lysates were diluted 1:2 in MES buffer (containing 32.5 mM MES monohydrate and $4 \mathrm{mM} \mathrm{CaCl}_{2}$ dihydrate). $20 \mu \mathrm{l}$ of each sample were transferred to black 96well plates and $30 \quad \mu l \quad 10 \mu \mathrm{M} \quad 20$-(4-methylumbelliferyl)-a-D-N-acetylneuraminic acid (MUNANA) were added. After $4 \mathrm{~h}$ of incubation at $37^{\circ} \mathrm{C}$ and gentle shaking, reaction was stopped with $150 \mu \mathrm{l}$ stop solution containing $0.1 \mathrm{M}$ glycine and 25\% ethanol. Neuramidasedependent cleavage of the substrate to the fluorescent product methylumbelliferone was quantified at an excitation of $360 \mathrm{~nm}$ and an emission at $455 \mathrm{~nm}$ was measured on a Cytation 3 Cell Imaging Multi-Mode Reader (BioTek, USA). Background from uninfected cells was subtracted and relative enzyme activity was used to quantify infection rates.

Measles virus (MV): Measles virus strain Schwarz was obtained from the lab of Karl-Klaus Conzelmann and propagated in Vero E6 cells as previously published ${ }^{42}$. Virus was diluted in serum-free medium and a viral dose corresponding to MOI 0.5 was added to $0-150 \mu \mathrm{M}$ dilutions of CLR01, CLR05 or PC for $30 \mathrm{~min}$ at $37^{\circ} \mathrm{C}$ before the mixtures were added to $2 \times 10^{4} \mathrm{~A} 549$ cells seeded the day before into black 96-well plates with a clear bottom (Corning Costar, USA). After $4 \mathrm{~h}$, cells were washed 3x with PBS and fresh medium containing 10\% FCS was added to the cells. 48 hours post infection, supernatants were discarded, cells were washed $1 \mathrm{x}$ with PBS and fixed with $70 \%$ acetone for $20 \mathrm{~min}$ at $4{ }^{\circ} \mathrm{C}$. After discarding the acetone, plates were allowed to dried completely before $50 \mu \mathrm{l}$ FITC-coupled mouse anti-measles antibody (Millipore, USA), 1:2000 diluted in PBS were added to each well. The plates were incubated in the dark overnight at $4^{\circ} \mathrm{C}$. After 3 washing steps with PBS, fluorescence at $528 \mathrm{~nm}$ (excitation at $485 \mathrm{~nm}$ ) was quantified on a Cytation 3 Cell Imaging Multi-Mode Reader (BioTek, USA). 


\section{Supplementary Figures}

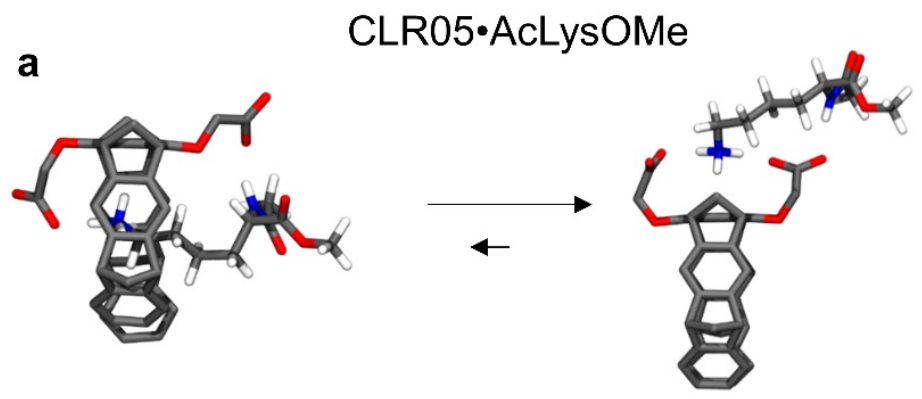

Inclusion complex (in)

Chelate form (out)

b
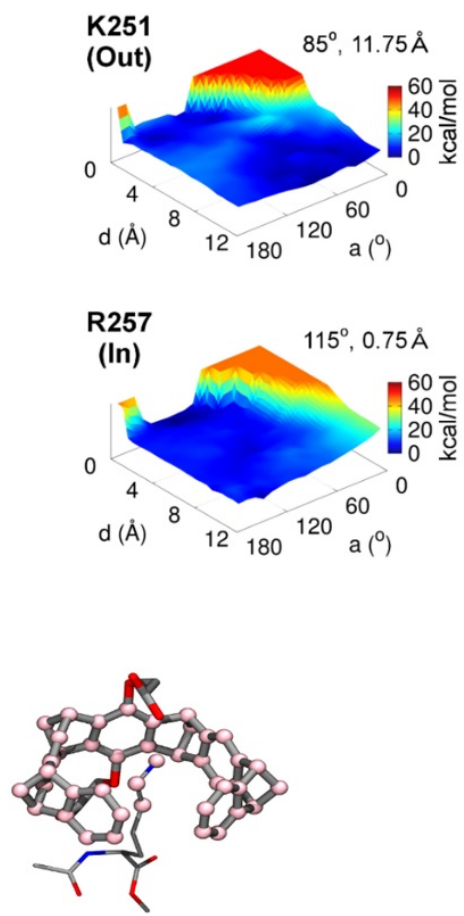

c

\begin{tabular}{ccccc}
\hline & \multicolumn{2}{c}{ Distance (Å) } & \multicolumn{2}{c}{ Angle ( $\left.{ }^{\circ}\right)$} \\
\hline Residue & eABF & Reference value $^{1}$ & eABF & Reference value $^{1}$ \\
\hline Lys $_{251}$ & 11.75 & $1.0 \pm 0.33$ & 85 & $97 \pm 14$ \\
Lys $_{253}$ & 0.25 & $1.1 \pm 0.37$ & 125 & $85 \pm 15$ \\
Lys $_{255}$ & 0.75 & $1.1 \pm 0.56$ & 95 & $93 \pm 16$ \\
Arg $_{257}$ & 0.75 & $1.7 \pm 0.75$ & 115 & $79 \pm 17$ \\
Arg $_{273}$ & 1.25 & $1.8 \pm 0.67$ & 75 & $72 \pm 15$ \\
Lys $_{281}$ & 7.25 & $1.0 \pm 0.59$ & 95 & $104 \pm 17$ \\
Lys $_{282}$ & 9.75 & $1.0 \pm 0.54$ & 65 & $103 \pm 18$ \\
\hline
\end{tabular}

${ }^{1}$ Reference values, which indicate inclusion, were obtained in REMD simulations of the inclusion complexes
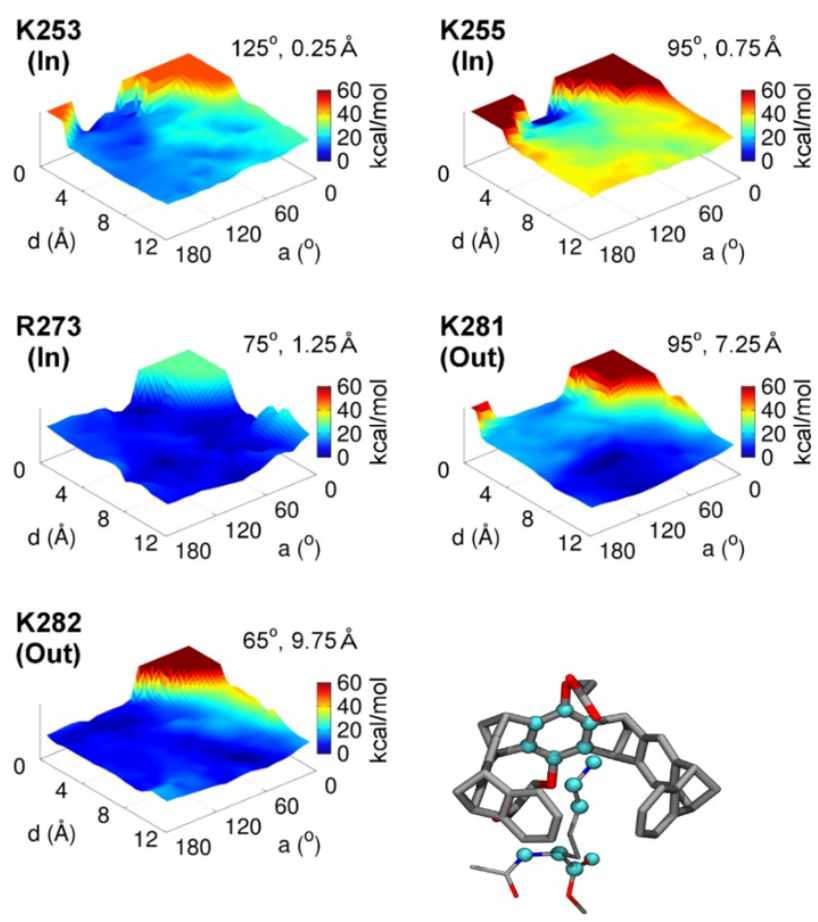

\begin{tabular}{|c|c|}
\hline Lys/Arg & $\Delta \Delta \mathrm{G}(\mathrm{kcal} / \mathrm{mol})$ \\
\hline K251 & $-1.9 \pm 0.3$ \\
\hline K253 & $-4.8 \pm 0.2$ \\
\hline K255 & $-3.9 \pm 0.2$ \\
\hline R257 & $-3.1 \pm 0.2$ \\
\hline R273 & $1.3 \pm 0.3$ \\
\hline K281 & $-2.8 \pm 0.2$ \\
\hline K282 & $-3.2 \pm 0.2$ \\
\hline
\end{tabular}

Supplementary Fig. 1. CLR05 has diminished ability (with respect to CLR01) to form inclusion complexes with lysine and arginine residues in PAP248-286. (a) Structures of complexes between CLR05 and the lysine derivative AcLysOMe optimized by QM/MM 
calculations (QM(B3LYP-D2/SVP) / CHARMM22) in explicit water (b) The free energy surfaces indicate that binding of CLR05 to residues at the $\mathrm{N}$-and C-terminal regions of PAP248-286 is not favored. This unfavorable binding is the case for K251, K281 and K282, as indicated by absence of a deep global minimum on the potential energy surfaces. For K253, K255, R257 and R273, the inclusion complex could be formed as shown by the major global minima. However, in K253 and R257, the interaction angles largely deviate from the reference REMD values in inclusion complexes. The collective variables used in these calculations were: $i$ ) the distance (d) between the center of mass (COM) of the pink atoms in CLR05 and the COM of the pink atoms in the lateral chain of Lys/Arg and, ii) the angle (a) between the COM of the cyan backbone atoms of Lys/Arg, the COM of the cyan atoms in the lateral chain of Lys/Arg and the COM of the cyan atoms in CLR05. (c) Values of the collective variables shown in the panel $\mathbf{b}$ based on eABF calculations and REMD simulations $(2.7 \mu \mathrm{s})$ as reference. The collective variables capture the extent of the inclusion of the Lys or Arg residues inside the tweezers' cavity. (d) Alchemical transformation calculations indicate that CLR01 forms more stable inclusion complexes than CLR05 for all residues, except R273. The relative stability of the inclusion complex of CLR05 with R273 is related to the position of R273, which makes possible additional extended hydrophobic interactions with the surrounding aliphatic residues. 
a

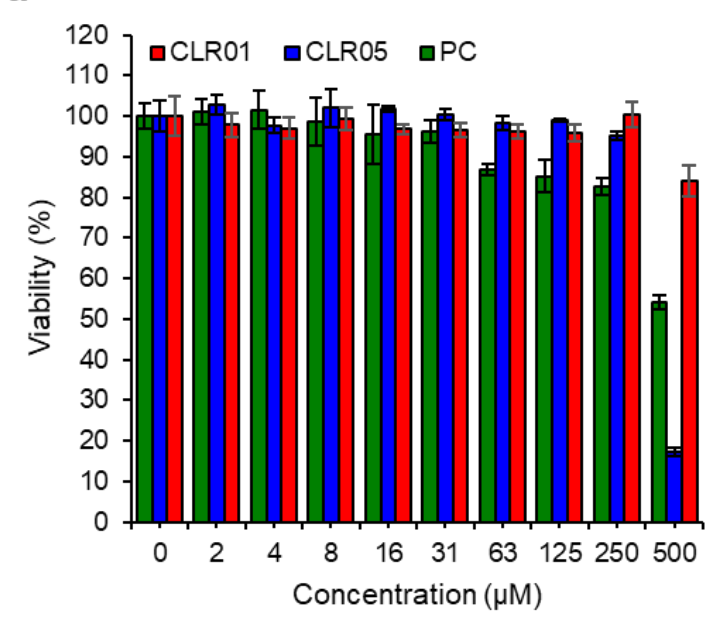

b

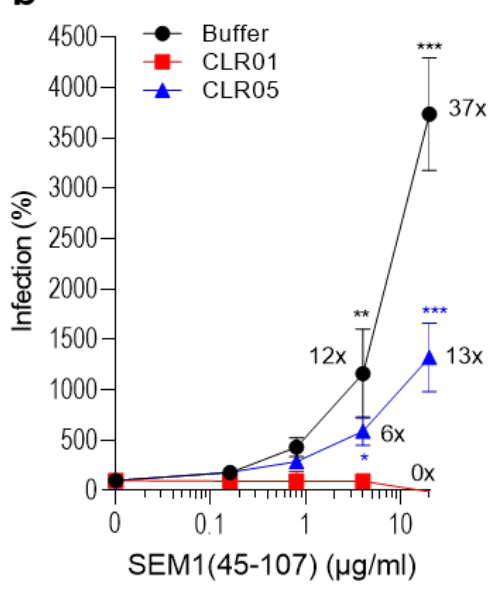

c

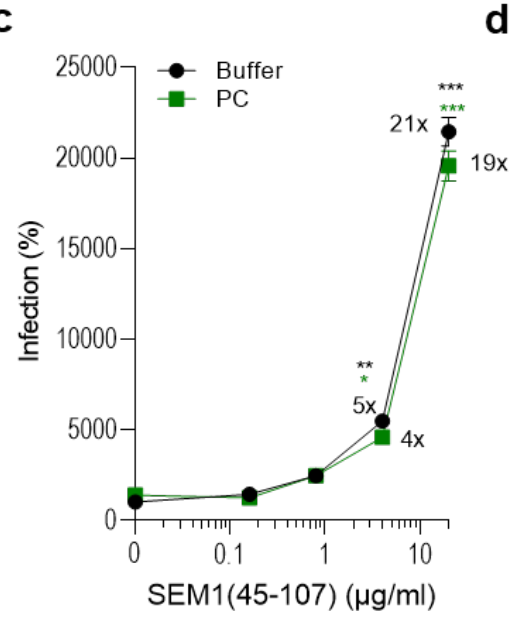

d

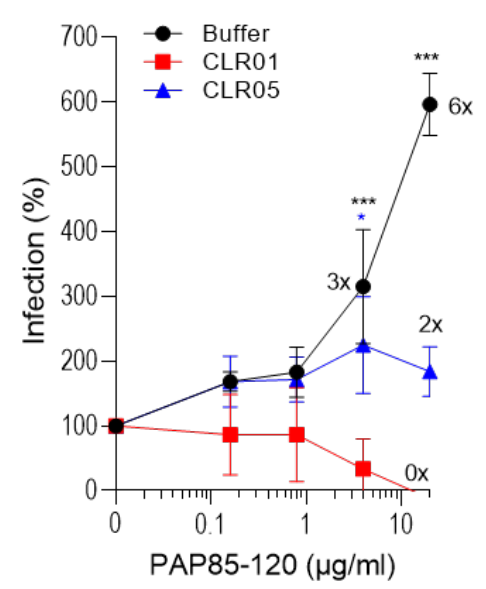

e

\begin{tabular}{|cccc|}
\hline & $\begin{array}{c}\mathbf{I C}_{50} \\
(\mu \mathrm{M})\end{array}$ & $\begin{array}{c}\mathbf{C C}_{50} \\
(\boldsymbol{\mu M})\end{array}$ & SI \\
CLR01 & 17.76 & $>500$ & $>26.15$ \\
CLR05 & 41.61 & 260.1 & 6.25 \\
PC & $\sim 116.8$ & $>500$ & $>4.28$ \\
\hline
\end{tabular}

Supplementary Fig. 2. CLR05 and PC are non-toxic, CLR05 decreases the HIV-1 enhancing activity of seminal amyloids. (a) CLR01, CLR05 and PC are non-cytotoxic in the applied concentrations in cell culture. TZM-bl cells $\left(1 \times 10^{4}\right.$ per well $)$ were seeded one day before incubation with the indicated CLR01, CLR05 and PC concentrations. After two days, metabolic activity of cells was assessed using CellTiter-Glo assay. Values were normalized to untreated cells and to determine \% viability. Mean values from biological triplicates \pm SD are shown. SEM1(45-107) (b and c) or PAP85-120 (d) fibrils were incubated with buffer or a 20fold molar excess of CLR01, CLR05 or PC for $10 \mathrm{~min}$ at room temperature. After preparing 5-fold dilution series of the mixtures, CCR5-tropic HIV-1 (1 ng/ml p24 antigen) was added and TZM-bl cells were inoculated with these samples. Values represent $\% \beta$-galactosidase activities (mean) compared to cells infected with virus only and are obtained from triplicate infections \pm SEM ( $n=9)$. Numbers above the symbols indicate $n$-fold enhancement of infection. (e) The half maximal inhibitory concentration $\left(\mathrm{IC}_{50}\right)$, half maximal cytotoxic concentration $\left(\mathrm{CC}_{50}\right)$ and the 
selectivity index (SI, i.e. $\mathrm{CC}_{50} / \mathrm{IC}_{50}$ ) values of CLR01, CLR05 and phosphate clip PC for experiments shown in Fig $2 \mathrm{c}$ and Supplementary Fig $2 \mathrm{a}$. 

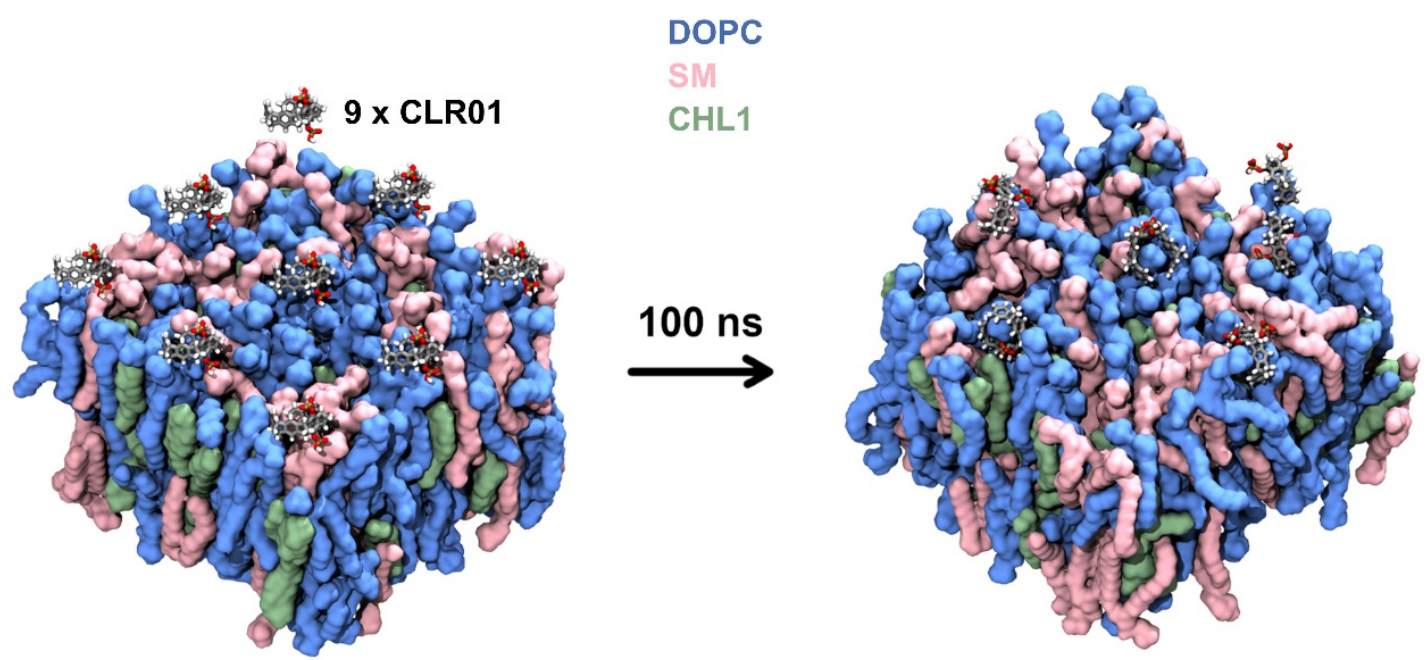

b
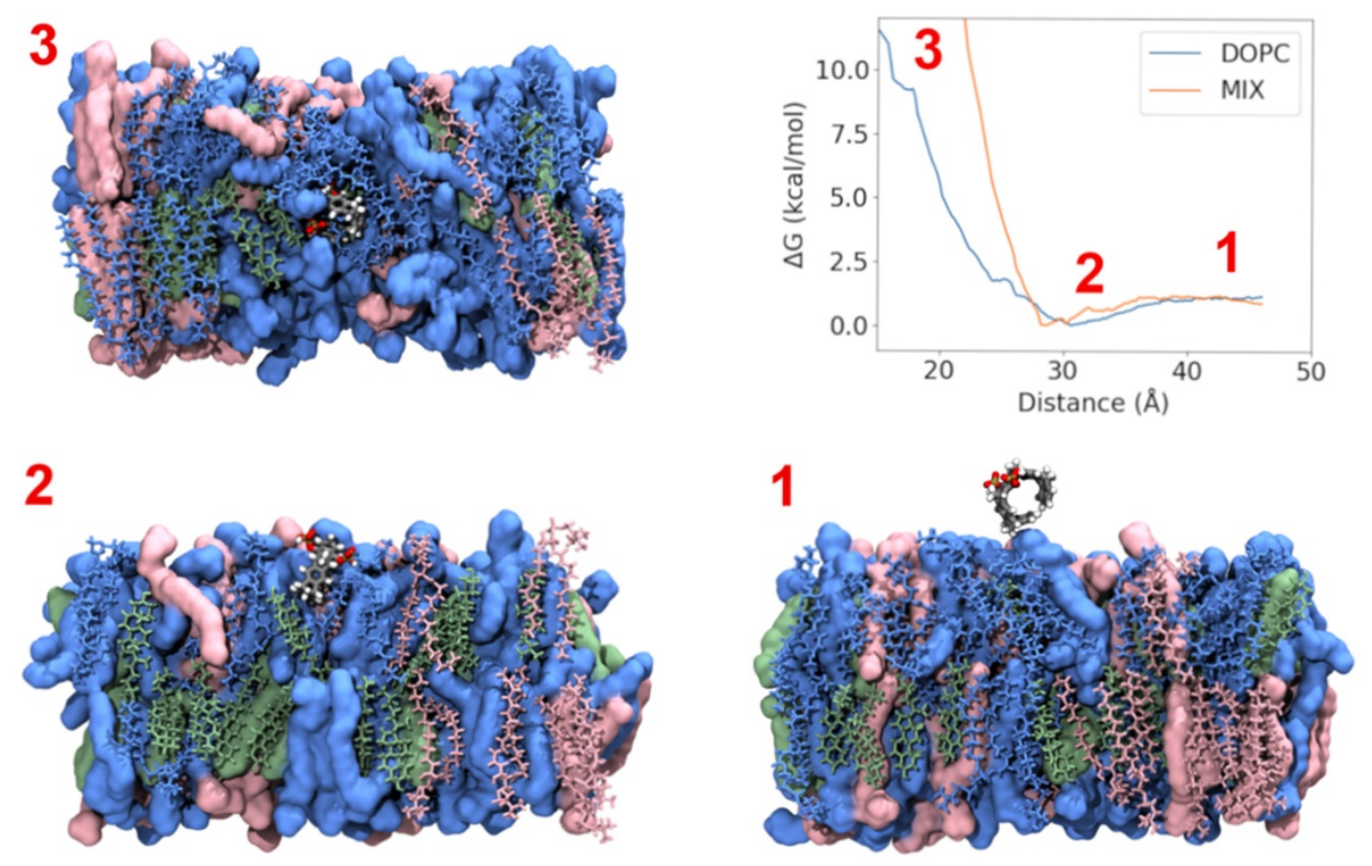

DOPC SM

CHL1

Supplementary Fig. 3. Several inclusion complexes are formed by CLR01 during the MD simulations with DOPC and mixed bilayers. (a) Initial and final snapshot of one of the replicas of the MD simulation performed with CLR01 and the mixed bilayer. CLR01 molecules are initially placed $4 \AA$ over the bilayer. (b) Free energy changes along the insertion of CLR01 in the DOPC and mixed bilayer models (MIX). Snapshots of the highlighted positions $\mathbf{1}, \mathbf{2}$ and $\mathbf{3}$ in the curves are shown. $\mathbf{1}$ corresponds to the tweezers in water, in $\mathbf{2}$ the tweezers are forming an inclusion complex with a head-group of a lipid (DOPC) located at the surface of the membrane and in $\mathbf{3}$, the tweezers are inside the bilayer. The color scheme is the same as in a) and the mixed bilayer is depicted. 

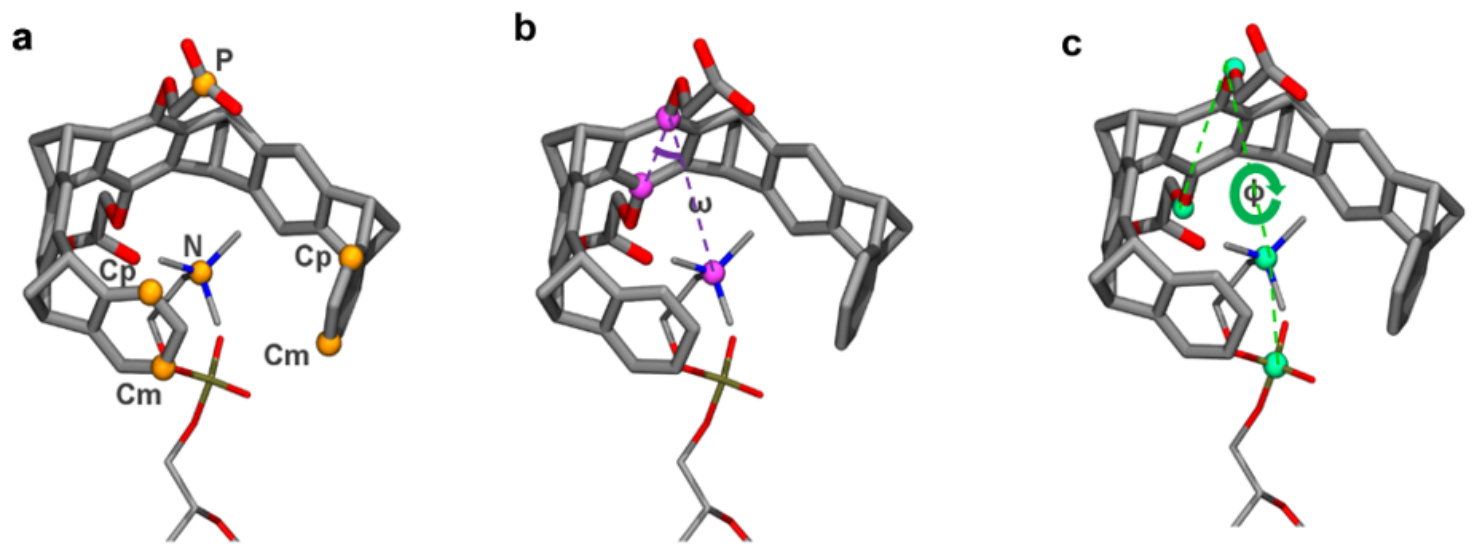

Supplementary Fig. 4. Angles and distances describing the tweezers/lipid interactions. Selected distances and angles used to characterize the inclusion complexes of CLR01, CLR05 and PC with amino acids/lipids. a) Distances $\mathrm{Cp}-\mathrm{Cp}, \mathrm{Cm}-\mathrm{Cm}$ and $\mathrm{P}-\mathrm{N}$. Cp $-\mathrm{Cp}$ and Cm - Cm distances indicate how distorted the tweezers are upon complexation, while the $\mathrm{P}-\mathrm{N}$ distance indicates how inserted is the side chain or the lipid head-group inside the tweezers' cavity. b) The angle $\omega$ is formed by the three atoms highlighted in pink and indicates the degree of penetration of the side chain/lipid inside the tweezer's cavity. c) The angle $\Phi$ is the dihedral formed by the atoms highlighted in green in CLR05 and the atoms highlighted in green in DOPC. $\Phi$ (not to be confused with $\Phi z$, the angle with respect to the z-axis shown in Fig. 3) indicates the relative orientation of the central benzene ring of CLR01/CLR05/PC with respect to the lipid's head-group. 
a
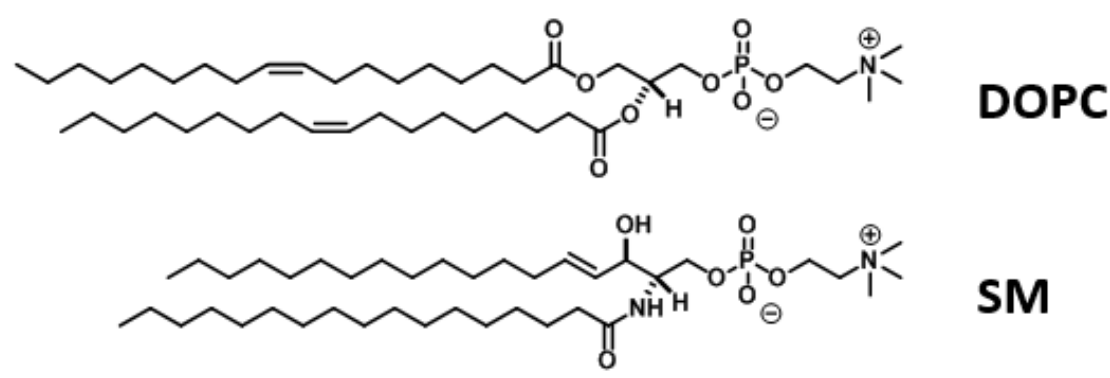

b

\begin{tabular}{ccc}
\hline Complex & $\begin{array}{c}\text { Relative Energy } \\
\text { (QM region, } \\
\mathrm{kcal} / \mathrm{mol}) \\
\text { (In membrane) }\end{array}$ & $\begin{array}{c}\text { Relative Energy } \\
\text { (QM region, } \\
\mathrm{kcal} / \mathrm{mol}) \\
\text { (In water) }\end{array}$ \\
\hline CLR01 - SM & $0 \pm 5$ & $0 \pm 5.2$ \\
CLR01 - DOPC & $28 \pm 7$ & $24 \pm 3.4$ \\
\hline
\end{tabular}

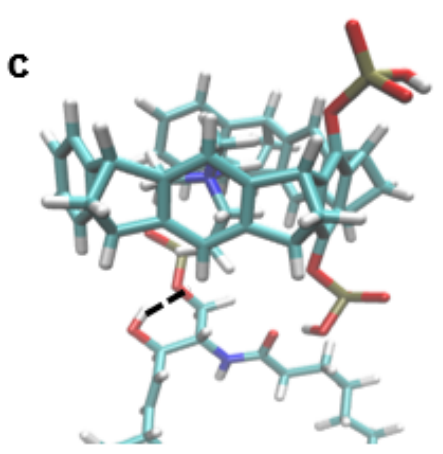

Supplementary Fig. 5. The results of QM/MM calculations predict a more stable complex of CLR01 with SM than with DOPC. (a) Chemical structure of DOPC and SM. (b) Relative QM energies from QM/MM calculations of the optimized complexes between CLR01 and DOPC or SM, both in the membrane and in water. (c) Inclusion complex of CLR01 with SM, highlighting the intramolecular hydrogen bond in SM. 
a NMR titration Sphingomyelin and CLR01:
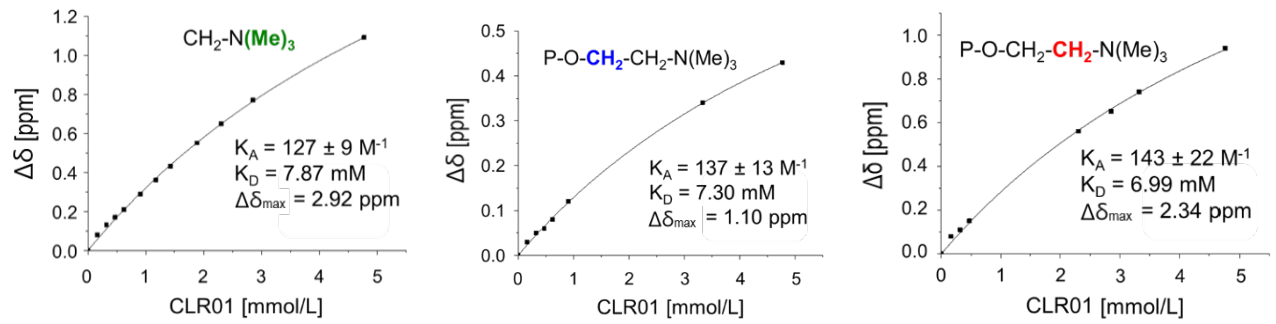

b NMR titration DOPC and CLR01:

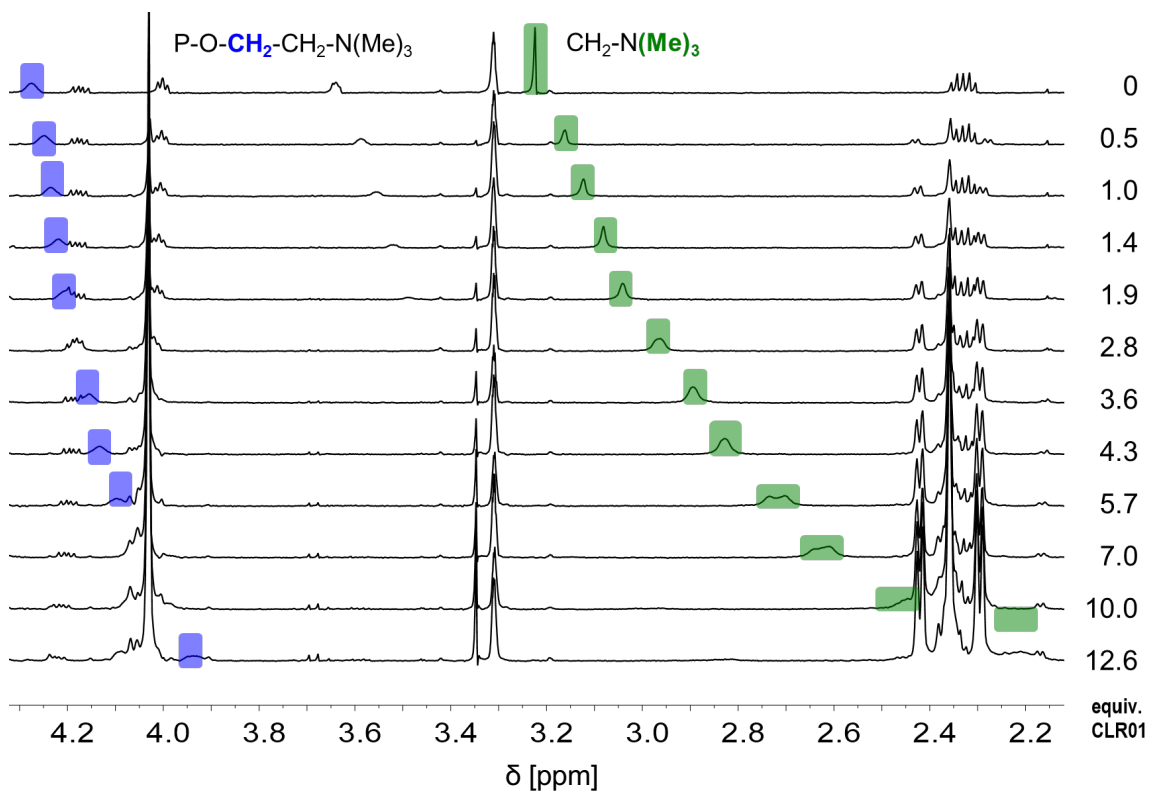

Binding curves DOPC and CLR01:
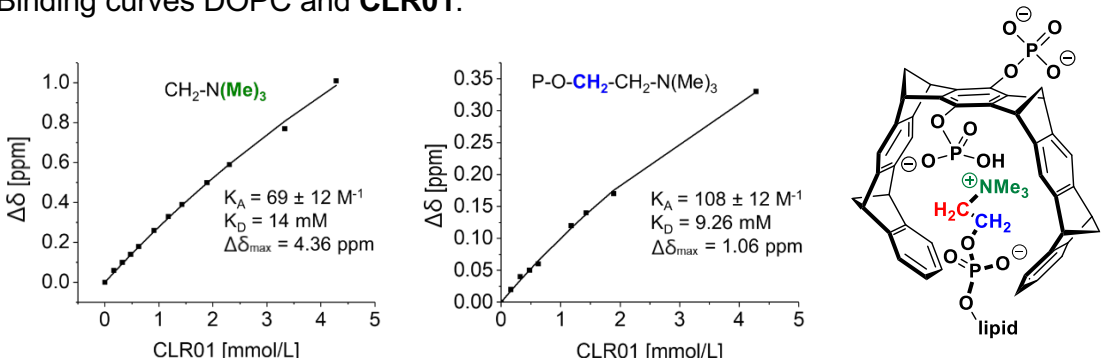
C NMR titration Sphingomyelin and PC:
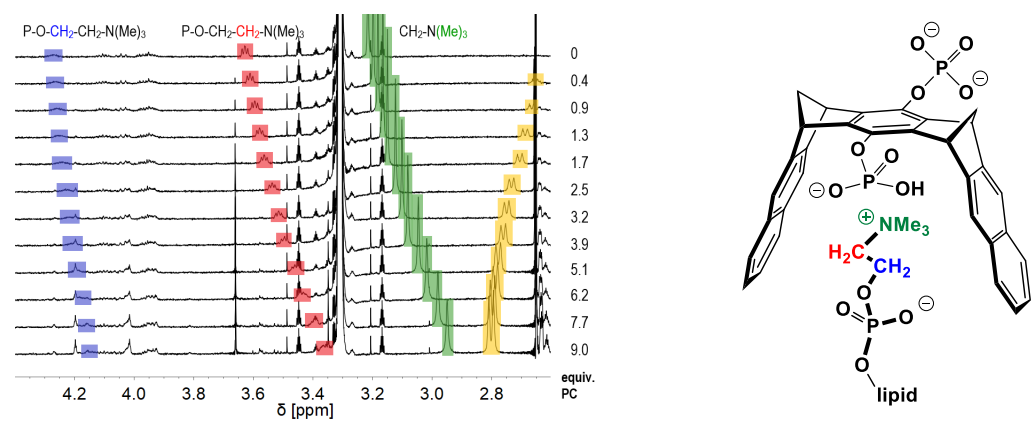

Binding curves Sphingomyelin and PC:
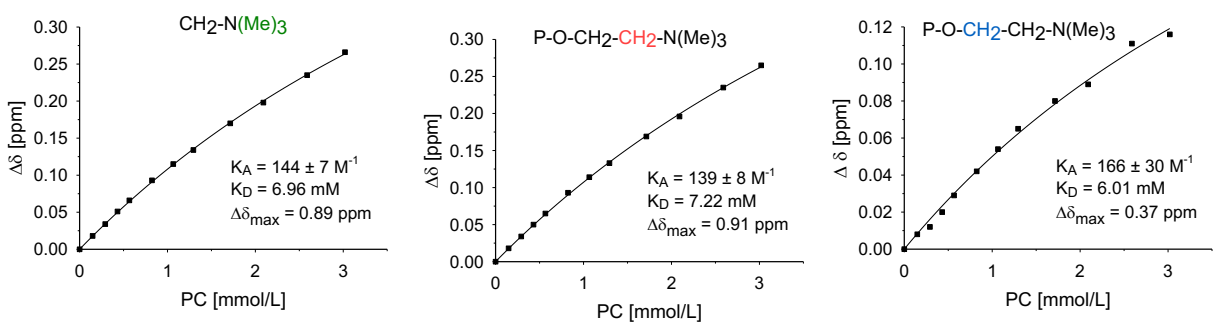

d NMR titration DOPC and PC
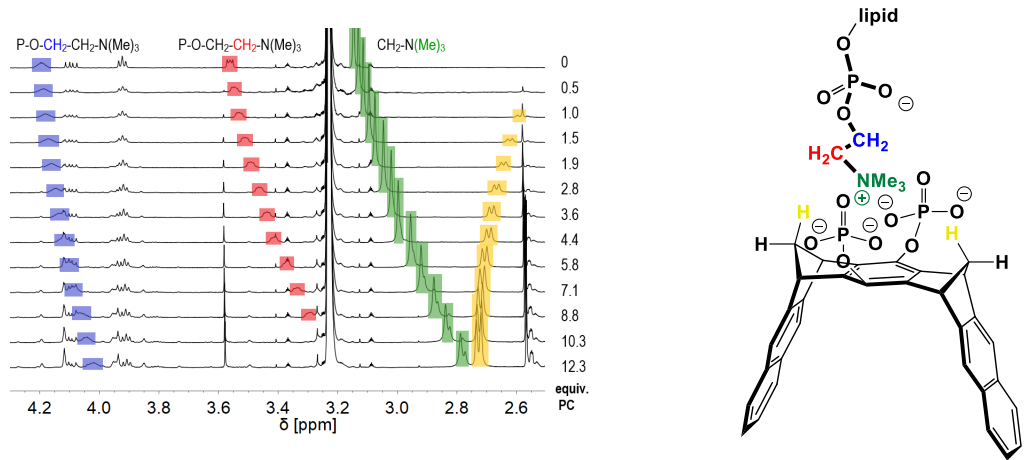

Binding curves DOPC and PC:
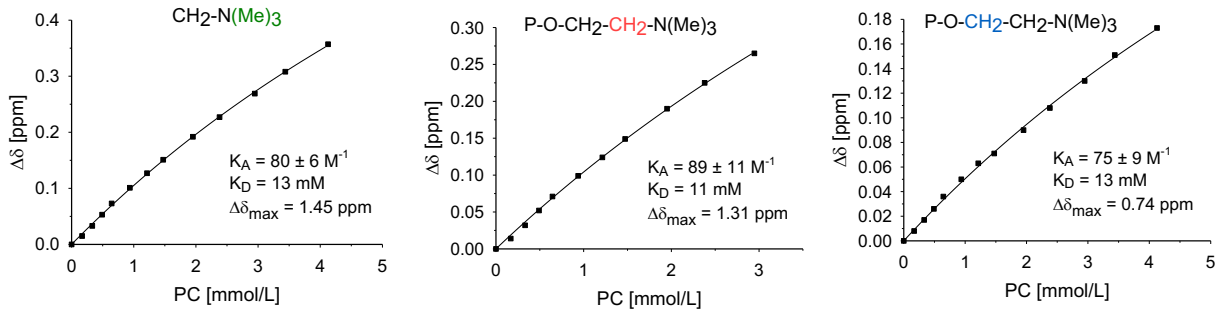
NMR titration Sphingomyelin and CLR05:
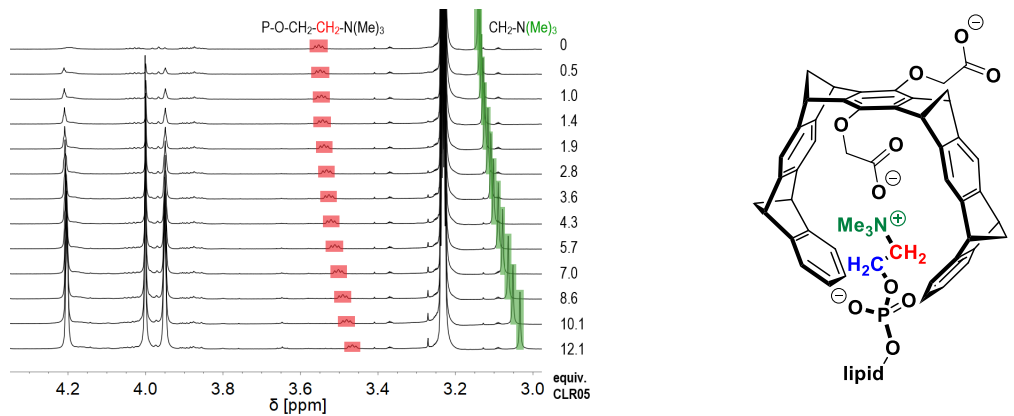

Binding curves Sphingomyelin and CLR05:
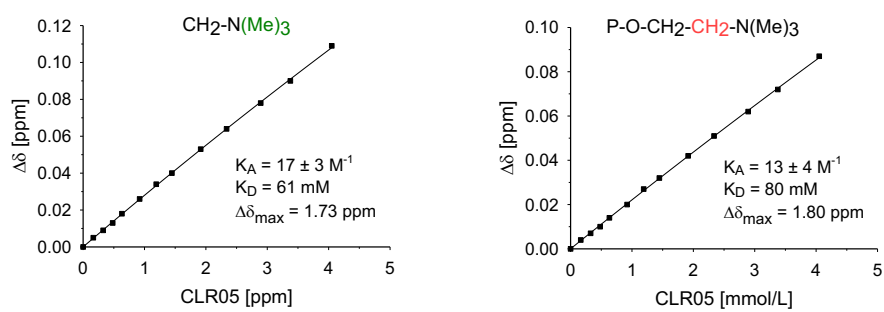

f NMR titration DOPC and CLR05:
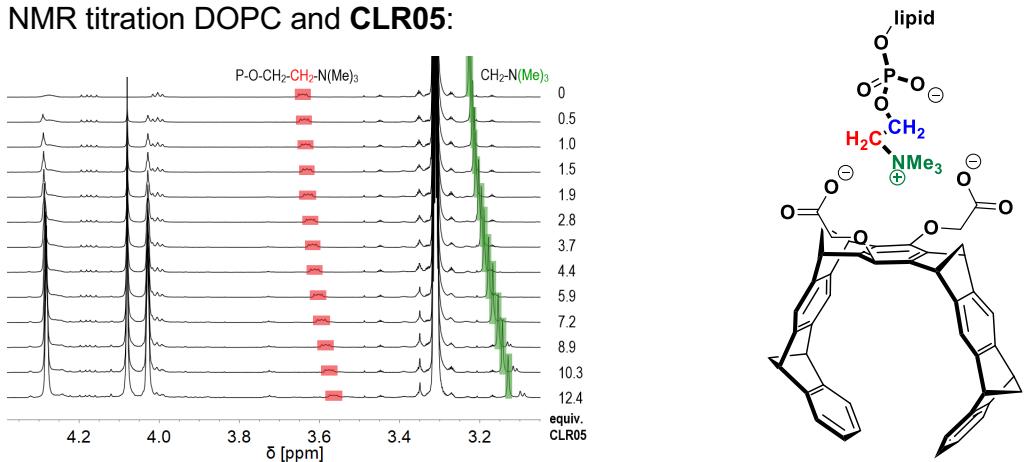

Binding curves DOPC and CLR05:
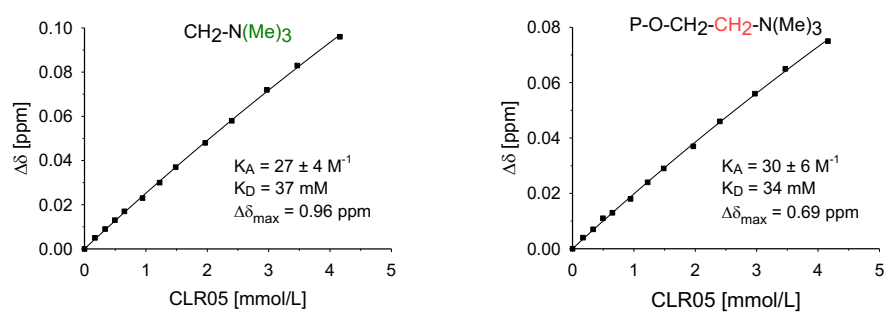

Supplementary Fig. 6. NMR titrations in $\mathbf{d}_{4}$-methanol between tweezers, clip and lipids. (a) Complex formation between CLR01 and phosphosphingomyelin (SM) monitored by NMR spectroscopy, continued from Fig. 4: corresponding binding curves for the $\mathrm{N}(\mathrm{Me})_{3}{ }^{+}$and both ethoxy methylene groups with the resulting affinity $\left(K_{\mathrm{A}} / K_{\mathrm{D}}\right)$ and $\Delta \delta_{\max }$ value obtained from nonlinear regression. (b) NMR titration between CLR01 and DOPC: Stacked plot with upfield shifting signals in green and blue, resulting binding curves with corresponding affinities and maximum chemical shift changes as well as Lewis structure illustrating the proposed binding 
mode; (c) NMR titration between PC and SM; (d) NMR titration between PC and DOPC; (e) NMR titration between CLR05 and SM; (f) NMR titration between CLR05 and DOPC. 
a
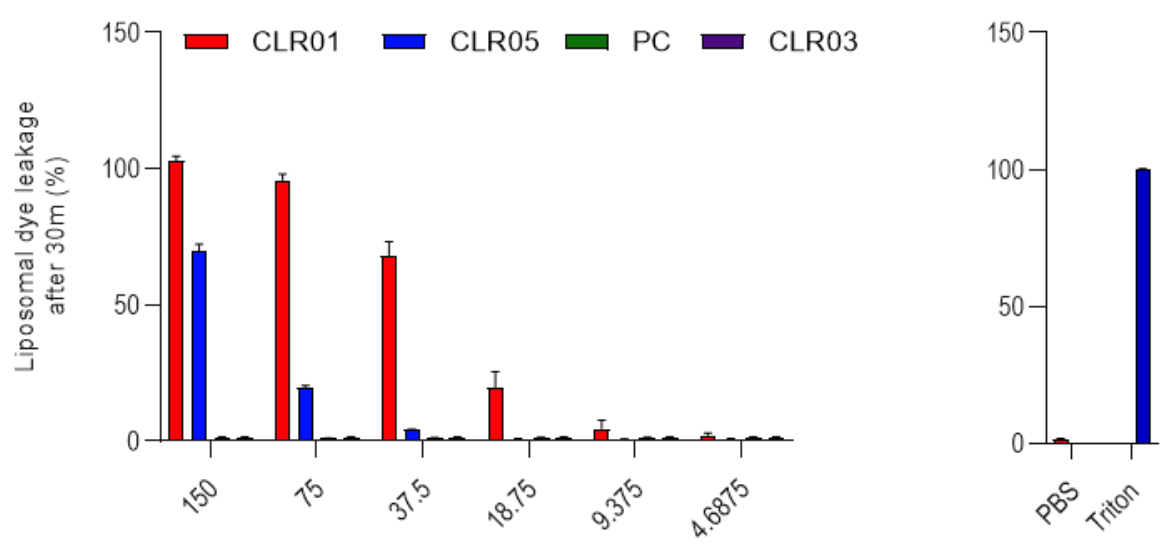

b

Tweezer $(\mu \mathrm{M})$

C
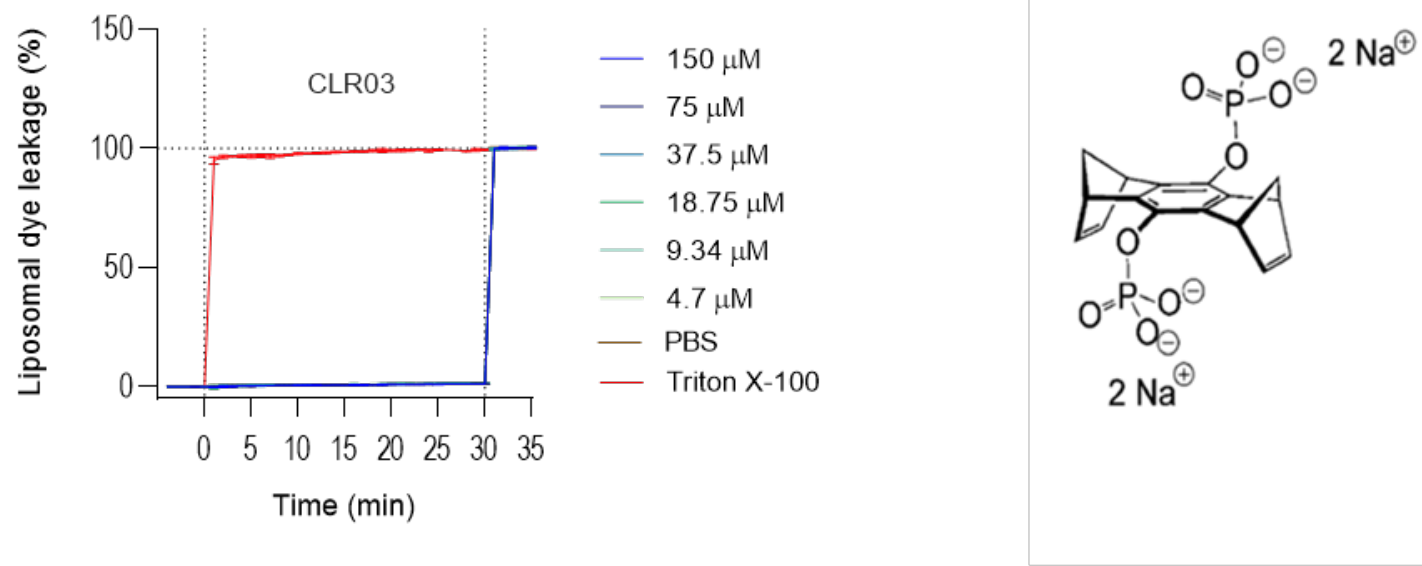

d

$\square \operatorname{CLR01} \mathrm{a} \square \mathrm{b} \square \mathrm{c} \square \mathrm{e} \square \mathrm{f} \square \mathrm{g} \square \mathrm{h}$

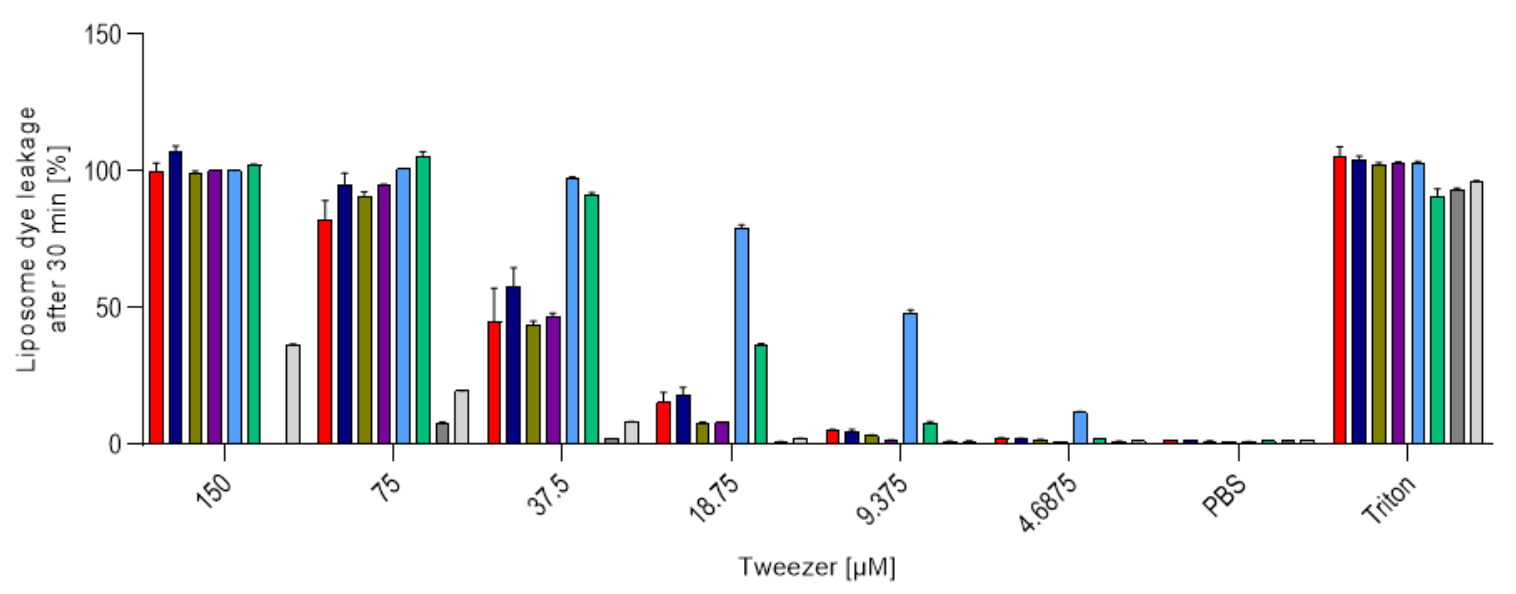

Supplementary Fig. 7 Peak dye leakage from liposomes incubated with tweezers for 30 min. (a) Dose-dependent liposome leakage induced by CLR01, CLR05, PC and CLR03 shown as the maximum reached after $30 \mathrm{~min}$ before addition for Triton X-100. Data shows means \pm SDs from two individual experiments, each performed in triplicates. (b) Timedependent leakage experiment with previously reported CLR03 performed in analogy to experiments shown in Fig. 5c. (d) Dose-dependent liposome leakage induced by CLR01 and advanced molecular tweezer derivatives shown as the maximum reached after 30 min before addition for Triton X-100. Data shows means \pm SDs from two individual experiments, each performed in triplicates. 

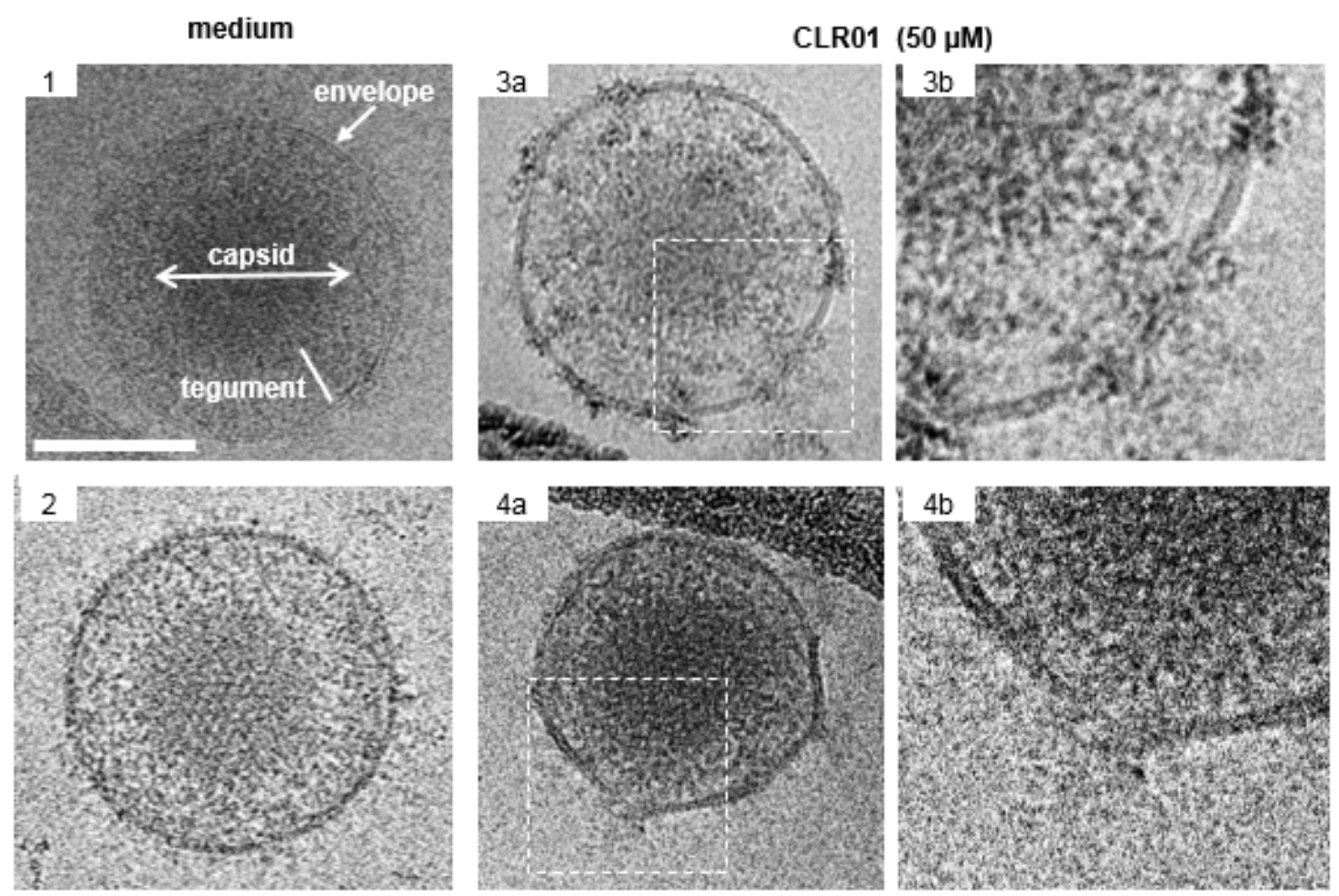

b

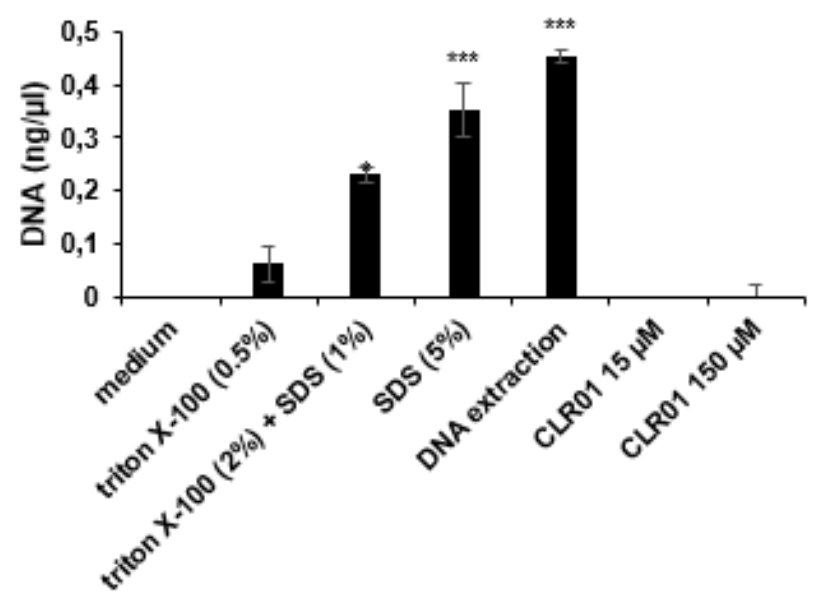

Supplementary Fig. 8. CLR01 interacts with the viral envelope of HCMV particles but does not destroy virion architecture. (a) Cryo-TEM of HCMV virions (strain TB40/E) after treatment with medium (1-2) or $50 \mu \mathrm{M}$ CLR01 (3a and 4a, higher magnifications in $3 \mathrm{~b}$ and $4 \mathrm{~b}$ ) for $30 \mathrm{~min}$ at $37^{\circ} \mathrm{C}$. Important virion structures are indicated in image 1. Note that CLR01treated virions show a discontinuous envelope and are decorated with electron-dense material at these sites. Scale bar is $100 \mathrm{~nm}$. (b) Cell-free supernatants of HCMV (strain TB40/E) were either subjected to DNA extraction or treated with indicated conditions for $30 \mathrm{~min}$ at $37^{\circ} \mathrm{C}$ prior to DNA quantification. Means \pm SDs from two individual experiments, each performed in triplicate. DNA measurements of identically treated cell supernatants of uninfected cells were subtracted to determine the DNA released from virus particles. 
a

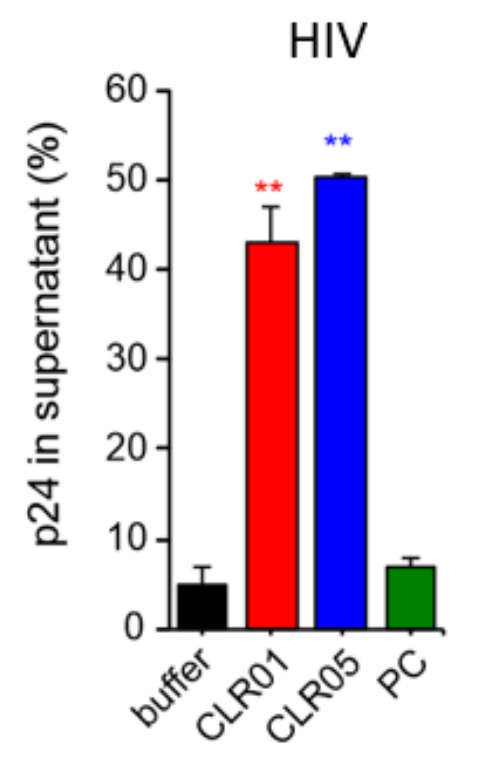

b

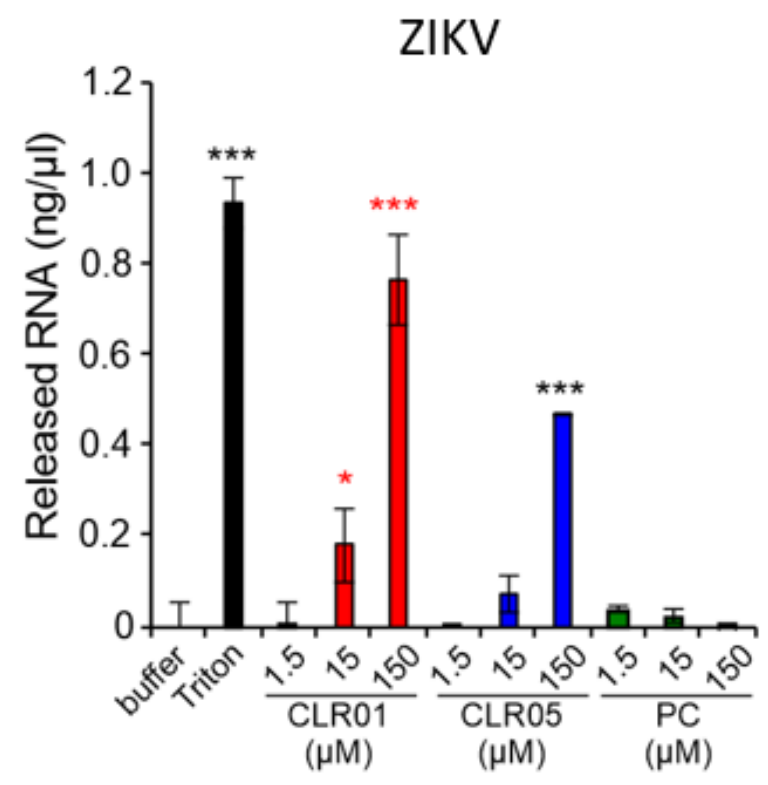

Supplementary Fig. 9. Tweezers destroy HIV and ZIKV particles. (a) CLR05 releases p24 capsid antigen from HIV particles. HIV-1 was incubated with buffer, $100 \mu$ M CLR05, or 100 $\mu \mathrm{M}$ CLR01, centrifuged, and the supernatant assayed for $\mathrm{p} 24$ antigen. Values represent means \pm SD $(n=3)$. Unpaired t-tests were applied to compare the buffer control to the CLR05 or CLR01 condition $(* *$ denotes $\mathrm{p}<0.01$ ). (b) CLR05 releases viral RNA. ZIKV MR766 was incubated with PBS, $150 \mu \mathrm{M}$ Triton X-100, 1.5-150 $\mu$ M CLR01 or PC or 15-300 $\mu$ M CLR05 for $30 \mathrm{~min}$ at $37{ }^{\circ} \mathrm{C}$. RNA concentrations of the samples were quantified using the QuantiFluor ${ }^{\circledR}$ RNA System and a Quantus Fluorometer. RNA levels of virus stock incubated with PBS were subtracted. Values represent means \pm SD $(n=3)$. One-way ANOVA (nonparametric, grouped), followed by Bonferroni's multiple comparison tests were applied to compare the buffer control to the different CLR01, CLR05 or PC conditions. 
A

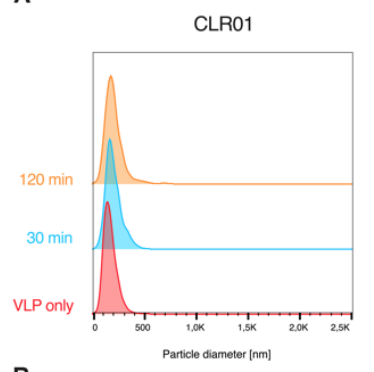

B

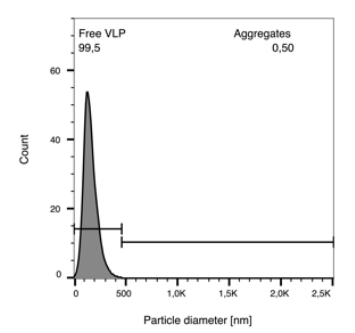

CLR03

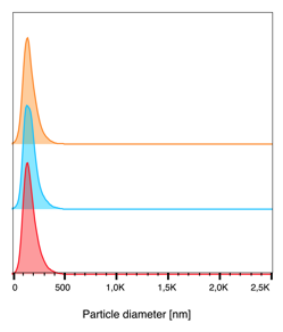

CLR05

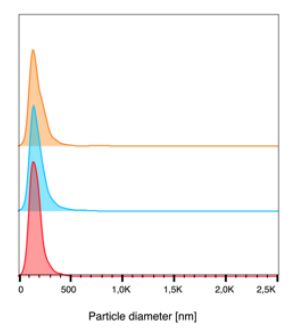

PC

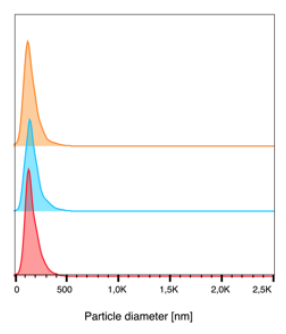

SEVI

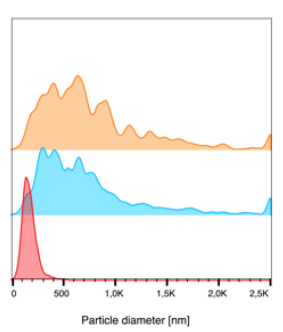

Supplementary Fig. 10. Molecular tweezers do not induce aggregation of virus-like particles (VLPs). (a) Representative size-distribution histograms acquired by F-NTA of YFPlabeled virus-like lentiviral particles after incubation with indicated compounds (Tweezers: 150 $\mu \mathrm{M}$, SEVI $100 \mu \mathrm{g} / \mathrm{ml}$ ) compared with VLPs diluted in PBS only. (b) Gating of free VLPs (left) and quantification of samples treated with compounds (right) after 30 and 120 minutes of incubation. Values represent means $\pm \operatorname{SD}(n=3)$. 
a

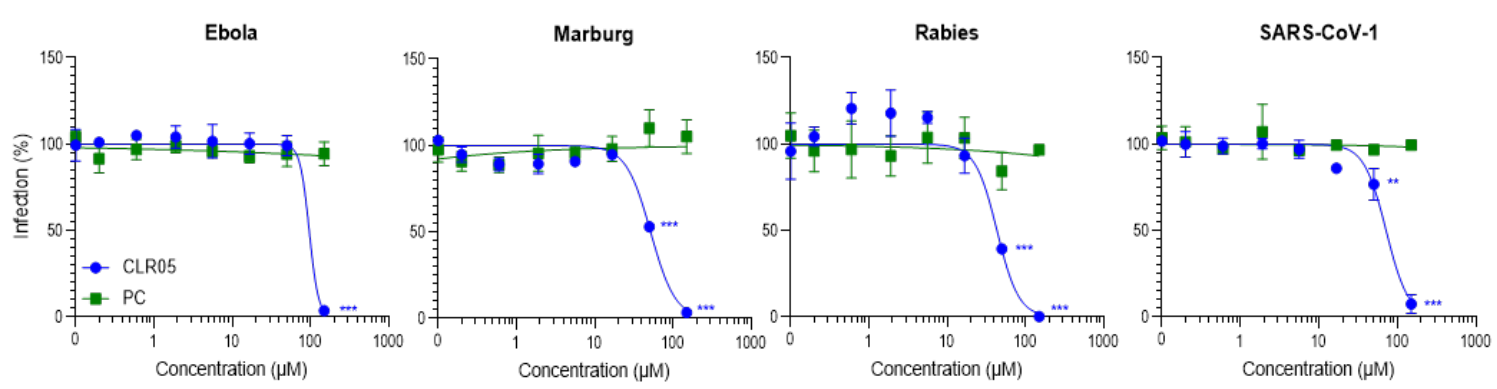

b
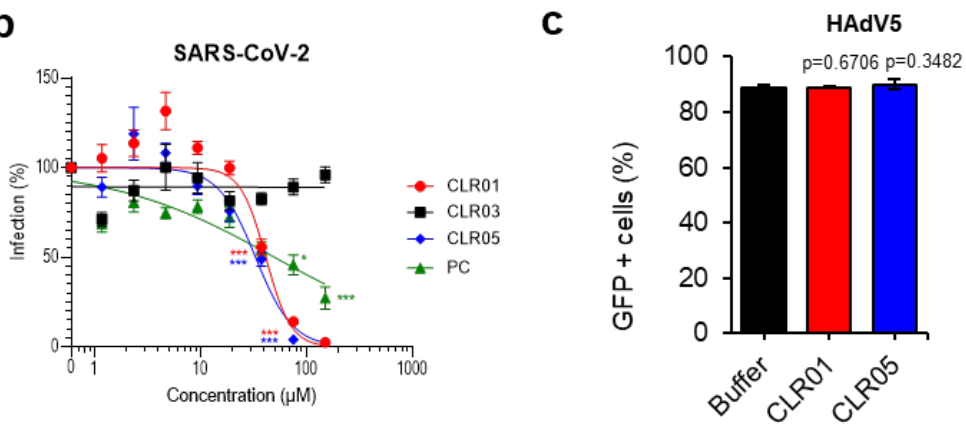

Supplementary Fig. 11. CLR05 inhibits pseudovirions but not Adenovirus. (a) CLR05 inhibits lentiviral particles pseudotyped with envelope proteins of Marburg, Ebola, Rabies virus and SARS-CoV-1. Pseudoparticles were incubated with CLR05 and PC and used to infect Huh-7 cells. After three days, infection rates were determined by quantifying firefly luciferase activity. Values represent \% reporter gene activities derived from triplicate infections (minus background activities derived from uninfected cells) normalized to values obtained for cells infected in the absence of compounds. Data of CLR01 and CLR03 inhibition on Marburg, Ebola, Rabies, SARS-CoV-1 pseudoparticle were recently published ${ }^{40}$. (b) CLR01 and CLR05 inhibit SARS-CoV-2 pseudoparticles. Virions were incubated with CLR01, CLR05, CLR03 and $\mathbf{P C}$ and used to infect $\mathrm{CaCo} 2$ cells. After two days, infection rates were determined by quantifying firefly luciferase activity. Values represent $\%$ reporter gene activities derived from triplicate infections (minus background activities derived from uninfected cells) normalized to values obtained for cells infected in the absence of compounds. Values represent means \pm SEM $(\mathrm{n}=3)$. (c) CLR05 has no effect on adenovirus. HAdV5 vector containing an EGFP expression cassette was titrated with buffer, $100 \mu \mathrm{M}$ CLR01 or CLR05 and incubated for $10 \mathrm{~min}$ at $37^{\circ} \mathrm{C}$ before A549 cells were infected with the pretreated virus. EGFP expression was analyzed one day post transduction using a Beckman-Coulter Gallios flow cytometer. 


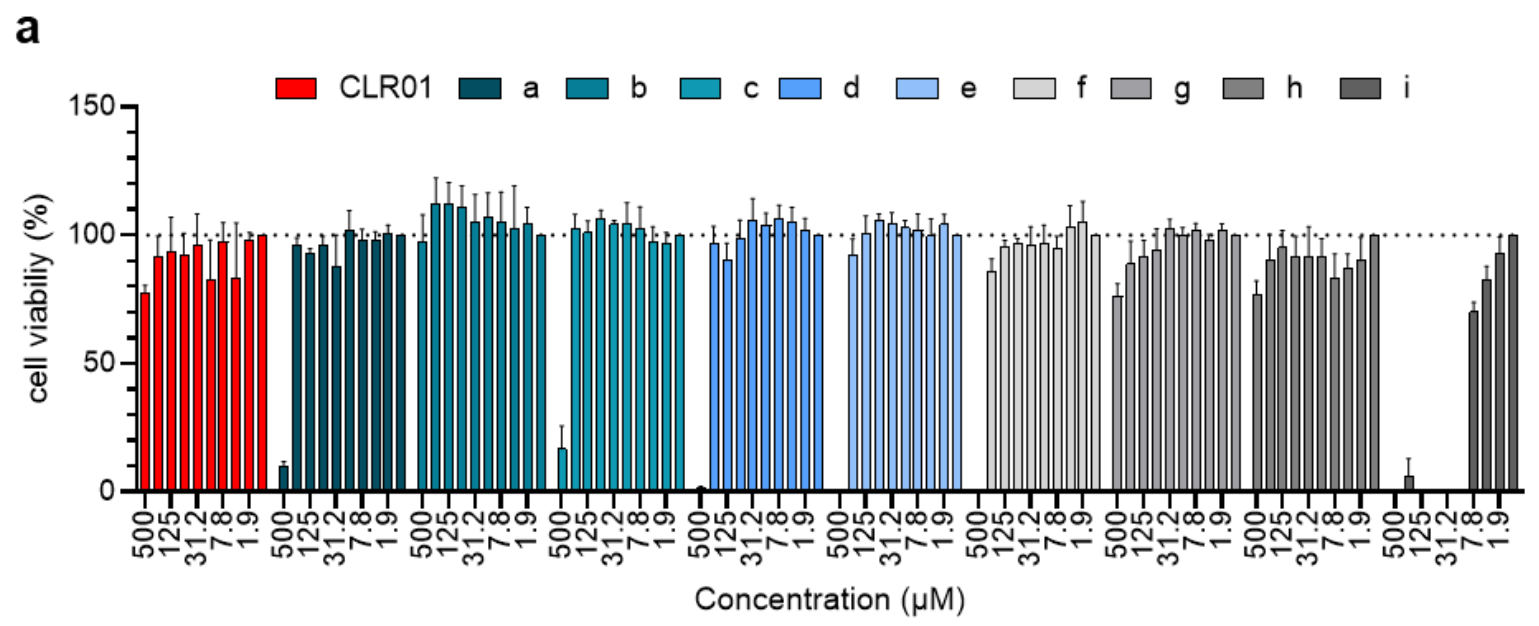

b

\begin{tabular}{|cccc|}
\hline & $\begin{array}{c}\mathrm{IC}_{50} \\
(\mu \mathrm{M})\end{array}$ & $\begin{array}{c}\mathrm{CC}_{50} \\
(\mu \mathrm{M})\end{array}$ & $\mathrm{SI}$ \\
$\mathrm{CLR01}$ & 35.44 & $>500$ & $>14.10$ \\
$\mathrm{a}$ & 21.56 & $\sim 376.6$ & $\sim 17.46$ \\
$\mathrm{~b}$ & 21.10 & $>500$ & $>23.69$ \\
$\mathrm{c}$ & 12.02 & $\sim 464.0$ & $\sim 38.60$ \\
$\mathrm{~d}$ & 28.72 & $\sim 342.4$ & $\sim 11.92$ \\
$\mathrm{e}$ & 8.78 & $\sim 299.6$ & $\sim 34.08$ \\
$\mathrm{f}$ & 6.64 & $\sim 294.1$ & $\sim 44.29$ \\
$\mathrm{~g}$ & 26.85 & $>500$ & $>18.62$ \\
$\mathrm{~h}$ & 27.04 & $>500$ & $>18.49$ \\
$\mathrm{i}$ & 77.62 & 8.98 & 0.115 \\
\hline
\end{tabular}

Supplementary Fig. 12. Advanced molecular tweezer derivatives with two aliphatic ester arms display improved activity against HIV-1 infection. (a) Effect of tweezer on cells was observed by CellTiterGlo. Therefore, tweezers were added to TZM-bl cells $(1.95-500 \mu \mathrm{M})$ and 2 days post treatment cell viability was quantified by measuring ATP amount. Values represent $\%$ cell viability derived from triplicate treatment normalized to values obtained for cells in the absence of compounds. Data shows means \pm SD from one individual experiment, performed in triplicates. (b) The half maximal inhibitory concentration $\left(\mathrm{IC}_{50}\right)$, half maximal cytotoxic concentration $\left(\mathrm{CC}_{50}\right)$ and the selectivity index (SI, i.e. $\left.\mathrm{CC}_{50} / \mathrm{IC}_{50}\right)$ values of tweezer CLR01 and advanced molecular tweezer derivates $\mathrm{a}-\mathrm{i}$ of experiments illustrated in Fig. $7 \mathrm{~b}$ and Supplementary Fig. 12a. 


\section{Supplementary Tables}

Supplementary Table 1. Binding events of CLR01, CLR05 and PC to the membranes.

max. number of binding events per replica of the simulation

\begin{tabular}{ccccc}
\hline Membrane composition & Number of molecules & CLR01 & CLR05 & PC \\
\hline DOPC & 9 & 8 & 4 & 9 \\
DOPC/SM/Chol & 9 & 6 & 4 & 9 \\
\hline
\end{tabular}


Supplementary Table 2. Distances and angles used to characterize the binding of the lipids to CLR01 during the MD simulations. Figure S4 illustrates the geometrical parameters listed below.

\begin{tabular}{|c|c|c|c|c|c|c|c|}
\hline Replica & $\begin{array}{c}\text { Binding } \\
\text { events }\end{array}$ & Lipid & $\begin{array}{c}C p-C p \\
(\AA)\end{array}$ & $\begin{array}{c}\mathrm{Cm}-\mathrm{Cm} \\
(\AA)\end{array}$ & $\begin{array}{c}P-N \\
(\AA)\end{array}$ & $\omega\left(^{\circ}\right)$ & $\Phi\left({ }^{\circ}\right)$ \\
\hline \multicolumn{8}{|c|}{ DOPC Bilayer } \\
\hline \multirow[t]{8}{*}{1} & 8 & DOPC & $7.03 \pm 0.61$ & $5.80 \pm 0.60$ & $6.86 \pm 0.91$ & $68.0 \pm 9.5$ & $20.4 \pm 12.0$ \\
\hline & & & $6.98 \pm 0.68$ & $5.81 \pm 0.64$ & $7.12 \pm 1.21$ & $67.6 \pm 11.3$ & $19.2 \pm 11.9$ \\
\hline & & & $6.44 \pm 0.99$ & $5.01 \pm 1.14$ & $9.39 \pm 3.19$ & $54.0 \pm 27.3$ & $34.9 \pm 24.3$ \\
\hline & & & $7.19 \pm 0.45$ & $5.93 \pm 0.51$ & $6.81 \pm 0.54$ & $71.9 \pm 7.0$ & $16.8 \pm 8.3$ \\
\hline & & & $7.27 \pm 0.52$ & $6.00 \pm 0.52$ & $6.89 \pm 0.79$ & $71.4 \pm 7.2$ & $15.5 \pm 9.5$ \\
\hline & & & $7.23 \pm 0.58$ & $5.95 \pm 0.63$ & $6.50 \pm 1.38$ & $70.7 \pm 11.8$ & $21.0 \pm 20.0$ \\
\hline & & & $7.07 \pm 0.77$ & $5.89 \pm 0.65$ & $7.55 \pm 0.51$ & $63.5 \pm 8.7$ & $23.8 \pm 9.9$ \\
\hline & & & $7.06 \pm 0.59$ & $5.87 \pm 0.57$ & $6.66 \pm 1.02$ & $67.4 \pm 8.3$ & $17.4 \pm 8.1$ \\
\hline \multirow[t]{6}{*}{2} & 6 & DOPC & $7.33 \pm 0.49$ & $6.05 \pm 0.56$ & $7.00 \pm 0.90$ & $71.9 \pm 8.8$ & $19.8 \pm 12.7$ \\
\hline & & & $7.40 \pm 0.43$ & $6.06 \pm 0.50$ & $5.54 \pm 0.85$ & $73.4 \pm 5.5$ & $16.2 \pm 9.0$ \\
\hline & & & $7.43 \pm 0.50$ & $6.19 \pm 0.54$ & $7.13 \pm 0.44$ & $69.2 \pm 6.6$ & $23.6 \pm 13.7$ \\
\hline & & & $7.41 \pm 0.51$ & $6.14 \pm 0.55$ & $7.25 \pm 0.79$ & $70.2 \pm 7.1$ & $20.7 \pm 12.2$ \\
\hline & & & $7.32 \pm 0.48$ & $6.04 \pm 0.51$ & $6.17 \pm 0.99$ & $70.2 \pm 7.1$ & $20.7 \pm 12.2$ \\
\hline & & & $7.11 \pm 0.58$ & $5.85 \pm 0.65$ & $6.94 \pm 1.00$ & $68.7 \pm 10.1$ & $20.2 \pm 14.0$ \\
\hline \multirow[t]{6}{*}{3} & 6 & DOPC & $6.47 \pm 1.03$ & $5.03 \pm 1.19$ & $9.10 \pm 3.29$ & $89.1 \pm 31.8$ & $58.2 \pm 46.9$ \\
\hline & & & $7.54 \pm 0.65$ & $6.39 \pm 0.70$ & $6.34 \pm 2.42$ & $65.9 \pm 6.8$ & $28.4 \pm 26.8$ \\
\hline & & & $7.36 \pm 0.46$ & $6.08 \pm 0.50$ & $6.49 \pm 0.97$ & $71.1 \pm 7.1$ & $17.1 \pm 9.0$ \\
\hline & & & $7.07 \pm 0.69$ & $5.90 \pm 0.72$ & $7.35 \pm 1.42$ & $64.4 \pm 15.1$ & $23.5 \pm 16.3$ \\
\hline & & & $7.42 \pm 0.50$ & $6.12 \pm 0.51$ & $6.42 \pm 0.99$ & $71.7 \pm 6.3$ & $18.9 \pm 8.8$ \\
\hline & & & $7.05 \pm 0.73$ & $5.74 \pm 0.81$ & $6.87 \pm 1.91$ & $70.8 \pm 14.7$ & $26.7 \pm 27.7$ \\
\hline \multicolumn{8}{|c|}{ Mixed Bilayer } \\
\hline \multirow[t]{6}{*}{1} & 6 & DOPC & $7.38 \pm 0.44$ & $6.01 \pm 0.48$ & $5.07 \pm 0.51$ & $73.7 \pm 6.9$ & $18.7 \pm 8.2$ \\
\hline & & DOPC & $7.08 \pm 0.54$ & $5.85 \pm 0.52$ & $6.95 \pm 0.72$ & $68.9 \pm 8.3$ & $17.7 \pm 8.5$ \\
\hline & & $\mathrm{SM}$ & $7.29 \pm 0.44$ & $5.99 \pm 0.49$ & $5.81 \pm 1.01$ & $70.9 \pm 6.7$ & $19.6 \pm 8.8$ \\
\hline & & SM & $7.23 \pm 0.69$ & $5.98 \pm 0.75$ & $7.36 \pm 1.78$ & $63.5 \pm 14.2$ & $29.8 \pm 25.3$ \\
\hline & & DOPC & $7.38 \pm 0.42$ & $6.07 \pm 0.48$ & $6.56 \pm 0.74$ & $74.4 \pm 5.9$ & $16.9 \pm 7.5$ \\
\hline & & DOPC & $6.92 \pm 0.92$ & $5.67 \pm 0.94$ & $6.48 \pm 0.86$ & $61.7 \pm 16.7$ & $29.2 \pm 26.4$ \\
\hline \multirow[t]{4}{*}{2} & 4 & DOPC & $6.96 \pm 0.74$ & $5.81 \pm 0.67$ & $7.63 \pm 0.60$ & $61.5 \pm 9.5$ & $24.1 \pm 12.5$ \\
\hline & & DOPC & $7.26 \pm 0.40$ & $6.02 \pm 0.44$ & $6.06 \pm 0.89$ & $71.3 \pm 5.5$ & $18.3 \pm 7.7$ \\
\hline & & DOPC & $7.42 \pm 0.39$ & $6.11 \pm 0.42$ & $7.11 \pm 0.32$ & $72.5 \pm 5.1$ & $17.6 \pm 6.1$ \\
\hline & & DOPC & $7.29 \pm 0.52$ & $6.05 \pm 0.56$ & $6.60 \pm 1.37$ & $69.0 \pm 8.4$ & $23.1 \pm 11.5$ \\
\hline \multirow[t]{5}{*}{3} & 5 & DOPC & $7.29 \pm 0.58$ & $6.00 \pm 0.61$ & $7.01 \pm 0.87$ & $70.4 \pm 9.5$ & $17.5 \pm 12.7$ \\
\hline & & SM & $7.48 \pm 0.39$ & $6.25 \pm 0.39$ & $7.09 \pm 0.41$ & $72.1 \pm 6.2$ & $16.3 \pm 8.6$ \\
\hline & & DOPC & $8.02 \pm 0.89$ & $6.84 \pm 1.00$ & $6.18 \pm 1.77$ & $64.7 \pm 9.8$ & $45.8 \pm 18.1$ \\
\hline & & DOPC & $6.62 \pm 1.04$ & $5.16 \pm 1.16$ & $8.30 \pm 3.29$ & $90.4 \pm 26.8$ & $38.7 \pm 32.9$ \\
\hline & & DOPC & $7.67 \pm 0.82$ & $6.41 \pm 0.94$ & $5.69 \pm 0.56$ & $65.7 \pm 6.1$ & $36.6 \pm 16.2$ \\
\hline
\end{tabular}


Supplementary Table 3. Distances and angles used to characterize the binding of the lipids to CLR05 during the MD simulations. Figure S4 illustrates the geometrical parameters listed below.

\begin{tabular}{cccccccc}
\hline Replica & $\begin{array}{c}\text { Binding } \\
\text { events }\end{array}$ & Lipid & $\begin{array}{c}\mathrm{Cp}-\mathrm{Cp} \\
(\AA)\end{array}$ & $\begin{array}{c}\mathrm{Cm}-\mathrm{Cm} \\
(\AA)\end{array}$ & $\begin{array}{c}\mathrm{P}-\mathrm{N} \\
(\AA)\end{array}$ & $\omega\left(^{\circ}\right)$ & $\Phi\left(^{\circ}\right)$ \\
\hline 1 & & \multicolumn{2}{c}{ DOPC Bilayer } \\
& 4 & DOPC & $7.41 \pm 0.55$ & $6.12 \pm 0.62$ & $6.59 \pm 1.48$ & $71.1 \pm 8.1$ & $23.9 \pm 18.8$ \\
& & & $7.25 \pm 0.72$ & $5.95 \pm 0.79$ & $7.01 \pm 2.18$ & $68.7 \pm 20.8$ & $31.3 \pm 23.5$ \\
& & & $7.27 \pm 0.57$ & $5.94 \pm 0.63$ & $6.65 \pm 1.51$ & $69.3 \pm 12.2$ & $22.7 \pm 14.9$ \\
\hline 3 & 1 & DOPC & $7.27 \pm 0.73$ & $5.95 \pm 0.83$ & $7.08 \pm 2.05$ & $74.3 \pm 19.2$ & $57.7 \pm 56.4$ \\
\hline & 3 & DOPC & $7.42 \pm 0.65$ & $6.16 \pm 0.75$ & $6.58 \pm 1.59$ & $68.8 \pm 13.1$ & $29.8 \pm 21.2$ \\
& & & $7.29 \pm 0.76$ & $5.98 \pm 0.86$ & $6.90 \pm 1.70$ & $73.8 \pm 18.2$ & $23.9 \pm 20.2$ \\
& & & $7.40 \pm 0.49$ & $6.11 \pm 0.52$ & $6.27 \pm 0.71$ & $69.0 \pm 6.0$ & $20.5 \pm 10.4$ \\
\hline \multirow{2}{*}{1} & 4 & DOPC & $7.42 \pm 0.53$ & $6.14 \pm 0.56$ & $6.66 \pm 0.94$ & $67.5 \pm 6.7$ & $25.4 \pm 13.5$ \\
& & DOPC & $7.44 \pm 0.51$ & $6.20 \pm 0.55$ & $6.47 \pm 0.83$ & $68.6 \pm 6.4$ & $24.8 \pm 14.3$ \\
& & DOPC & $7.41 \pm 0.50$ & $6.12 \pm 0.53$ & $6.38 \pm 0.77$ & $68.7 \pm 6.1$ & $19.9 \pm 10.6$ \\
& & DOPC & $7.44 \pm 0.47$ & $6.15 \pm 0.50$ & $6.23 \pm 0.74$ & $69.1 \pm 5.5$ & $20.3 \pm 11.0$ \\
\hline 2 & 3 & DOPC & $9.17 \pm 0.75$ & $8.57 \pm 0.87$ & $6.84 \pm 0.77$ & $64.1 \pm 5.1$ & $30.0 \pm 11.9$ \\
& & DOPC & $7.36 \pm 0.47$ & $6.09 \pm 0.52$ & $6.75 \pm 0.82$ & $69.0 \pm 6.3$ & $18.5 \pm 8.0$ \\
& & DOPC & $7.35 \pm 0.51$ & $6.04 \pm 0.54$ & $6.51 \pm 0.86$ & $68.3 \pm 6.6$ & $22.4 \pm 10.0$ \\
\hline 3 & 3 & DOPC & $7.37 \pm 0.48$ & $6.07 \pm 0.54$ & $6.29 \pm 0.70$ & $69.9 \pm 6.1$ & $19.7 \pm 9.5$ \\
& & DOPC & $7.36 \pm 0.55$ & $6.09 \pm 0.62$ & $6.54 \pm 1.23$ & $67.4 \pm 9.8$ & $24.3 \pm 17.4$ \\
& & SM & $7.46 \pm 0.47$ & $6.15 \pm 0.51$ & $6.34 \pm 0.75$ & $68.7 \pm 5.5$ & $18.9 \pm 9.7$ \\
\hline
\end{tabular}


Supplementary Table 4. Distances and angles used to characterize the binding of the lipids to PC during the MD simulations. Figure S4 illustrates the geometrical parameters listed below.

\begin{tabular}{|c|c|c|c|c|c|c|c|}
\hline Replica & $\begin{array}{c}\text { Binding } \\
\text { events }\end{array}$ & Lipid & $\begin{array}{c}C p-C p \\
(\AA)\end{array}$ & $\begin{array}{c}\mathrm{Cm}-\mathrm{Cm} \\
(\AA)\end{array}$ & $\begin{array}{c}\mathrm{P}-\mathrm{N} \\
(\AA)\end{array}$ & $\omega\left(^{\circ}\right)$ & $\Phi\left(^{\circ}\right)$ \\
\hline \multicolumn{8}{|c|}{ DOPC Bilayer } \\
\hline \multirow[t]{9}{*}{1} & 9 & DOPC & $9.06 \pm 0.41$ & $9.96 \pm 0.50$ & $6.87 \pm 0.47$ & $72.3 \pm 7.1$ & $86.8 \pm 49.1$ \\
\hline & & & $8.99 \pm 0.38$ & $9.83 \pm 0.49$ & $6.89 \pm 0.58$ & $74.9 \pm 6.6$ & $115.0 \pm 30.8$ \\
\hline & & & $9.08 \pm 0.45$ & $9.99 \pm 0.52$ & $7.22 \pm 0.45$ & $67.9 \pm 7.3$ & $61.3 \pm 23.6$ \\
\hline & & & $9.07 \pm 0.55$ & $9.96 \pm 0.68$ & $9.17 \pm 3.02$ & $63.8 \pm 24.3$ & $83.3 \pm 43.2$ \\
\hline & & & $9.12 \pm 0.43$ & $10.01 \pm 0.54$ & $6.84 \pm 0.49$ & $73.4 \pm 7.6$ & $92.6 \pm 42.3$ \\
\hline & & & $9.02 \pm 0.43$ & $9.97 \pm 0.53$ & $6.95 \pm 0.51$ & $72.2 \pm 7.4$ & $70.2 \pm 32.7$ \\
\hline & & & $9.11 \pm 0.43$ & $10.04 \pm 0.54$ & $6.89 \pm 0.70$ & $72.6 \pm 8.8$ & $78.3 \pm 39.6$ \\
\hline & & & $9.09 \pm 0.42$ & $9.99 \pm 0.53$ & $6.85 \pm 0.49$ & $73.4 \pm 8.5$ & $109.1 \pm 41.1$ \\
\hline & & & $9.17 \pm 0.48$ & $10.08 \pm 0.56$ & $7.20 \pm 0.66$ & $68.1 \pm 10.2$ & $67.4 \pm 30.8$ \\
\hline \multirow[t]{9}{*}{2} & 9 & DOPC & $9.04 \pm 0.43$ & $9.89 \pm 0.53$ & $6.89 \pm 0.78$ & $74.1 \pm 8.2$ & $86.2 \pm 41.9$ \\
\hline & & & $9.12 \pm 0.43$ & $10.04 \pm 0.53$ & $6.66 \pm 0.67$ & $72.6 \pm 6.8$ & $96.3 \pm 37.4$ \\
\hline & & & $9.11 \pm 0.44$ & $10.02 \pm 0.55$ & $6.88 \pm 0.77$ & $73.2 \pm 9.5$ & $83.7 \pm 36.2$ \\
\hline & & & $9.10 \pm 0.47$ & $10.05 \pm 0.55$ & $7.35 \pm 0.65$ & $65.1 \pm 7.1$ & $45.9 \pm 20.0$ \\
\hline & & & $9.10 \pm 0.42$ & $10.02 \pm 0.52$ & $6.81 \pm 0.51$ & $72.7 \pm 7.1$ & $78.4 \pm 49.7$ \\
\hline & & & $9.10 \pm 0.43$ & $9.98 \pm 0.53$ & $6.70 \pm 0.86$ & $76.1 \pm 8.3$ & $95.6 \pm 22.5$ \\
\hline & & & $9.03 \pm 0.42$ & $9.91 \pm 0.54$ & $6.92 \pm 0.58$ & $73.1 \pm 8.2$ & $110.6 \pm 52.5$ \\
\hline & & & $9.09 \pm 0.43$ & $9.97 \pm 0.54$ & $6.85 \pm 0.48$ & $73.6 \pm 7.1$ & $92.2 \pm 46.7$ \\
\hline & & & $8.96 \pm 0.41$ & $9.85 \pm 0.52$ & $6.88 \pm 0.45$ & $73.5 \pm 7.8$ & $36.4 \pm 29.7$ \\
\hline \multirow[t]{9}{*}{3} & 9 & DOPC & $9.04 \pm 0.51$ & $9.92 \pm 0.63$ & $9.28 \pm 2.89$ & $76.2 \pm 26.5$ & $87.3 \pm 40.8$ \\
\hline & & & $9.02 \pm 0.45$ & $9.95 \pm 0.55$ & $7.03 \pm 0.99$ & $72.4 \pm 9.04$ & $92.3 \pm 33.5$ \\
\hline & & & $9.03 \pm 0.43$ & $9.92 \pm 0.52$ & $7.26 \pm 0.48$ & $66.9 \pm 7.9$ & $67.5 \pm 55.6$ \\
\hline & & & $9.05 \pm 0.43$ & $9.95 \pm 0.54$ & $6.93 \pm 0.48$ & $73.0 \pm 7.5$ & $71.5 \pm 37.5$ \\
\hline & & & $9.08 \pm 0.46$ & $9.97 \pm 0.57$ & $6.91 \pm 1.19$ & $73.1 \pm 9.8$ & $102.6 \pm 32.4$ \\
\hline & & & $9.07 \pm 0.48$ & $9.95 \pm 0.57$ & $7.16 \pm 1.03$ & $69.5 \pm 8.5$ & $61.0 \pm 31.2$ \\
\hline & & & $9.02 \pm 0.44$ & $9.93 \pm 0.55$ & $6.91 \pm 0.60$ & $72.2 \pm 8.2$ & $106.1 \pm 42.6$ \\
\hline & & & $9.12 \pm 0.41$ & $10.02 \pm 0.52$ & $6.68 \pm 0.60$ & $73.7 \pm 7.2$ & $95.7 \pm 39.3$ \\
\hline & & & $9.12 \pm 0.41$ & $10.02 \pm 0.52$ & $6.78 \pm 0.47$ & $74.1 \pm 7.4$ & $91.0 \pm 43.9$ \\
\hline
\end{tabular}

\section{Supplementary Table 4 (cont.)}

\begin{tabular}{|c|c|c|c|c|c|c|c|}
\hline Replica & $\begin{array}{l}\text { Binding } \\
\text { events }\end{array}$ & Lipid & $\begin{array}{c}\mathrm{Cp}-\mathrm{Cp} \\
(\AA)\end{array}$ & $\begin{array}{c}\mathrm{Cm}-\mathrm{Cm} \\
(\AA)\end{array}$ & $\begin{array}{c}\mathrm{P}-\mathrm{N} \\
(\AA)\end{array}$ & $\omega\left(^{\circ}\right)$ & $\Phi\left({ }^{\circ}\right)$ \\
\hline \multicolumn{8}{|c|}{ Mixed Bilayer } \\
\hline \multirow[t]{7}{*}{1} & 7 & SM & $8.93 \pm 0.49$ & $9.86 \pm 0.58$ & $7.66 \pm 0.93$ & $62.7 \pm 8.7$ & $50.3 \pm 17.9$ \\
\hline & & SM & $9.16 \pm 0.43$ & $10.07 \pm 0.53$ & $6.92 \pm 0.48$ & $71.6 \pm 7.3$ & $105.3 \pm 38.2$ \\
\hline & & SM & $9.10 \pm 0.42$ & $10.00 \pm 0.52$ & $6.68 \pm 0.76$ & $73.1 \pm 7.0$ & $75.0 \pm 39.4$ \\
\hline & & DOPC & $9.01 \pm 0.53$ & $9.93 \pm 0.66$ & $9.58 \pm 2.83$ & $88.1 \pm 27.7$ & $77.2 \pm 48.3$ \\
\hline & & DOPC & $9.04 \pm 0.41$ & $9.90 \pm 0.50$ & $6.91 \pm 0.48$ & $72.7 \pm 7.1$ & $87.5 \pm 36.0$ \\
\hline & & SM & $9.11 \pm 0.42$ & $10.00 \pm 0.53$ & $6.88 \pm 0.50$ & $72.4 \pm 7.6$ & $110.0 \pm 40.4$ \\
\hline & & DOPC & $9.03 \pm 0.48$ & $9.92 \pm 0.60$ & $6.92 \pm 0.80$ & $74.1 \pm 9.05$ & $62.6 \pm 37.0$ \\
\hline \multirow[t]{6}{*}{2} & 6 & DOPC & $9.04 \pm 0.45$ & $9.93 \pm 0.57$ & $6.98 \pm 1.09$ & $74.0 \pm 11.3$ & $85.9 \pm 41.9$ \\
\hline & & SM & $9.14 \pm 0.43$ & $10.05 \pm 0.54$ & $9.58 \pm 3.11$ & $93.6 \pm 40.4$ & $78.4 \pm 37.2$ \\
\hline & & SM & $9.06 \pm 0.41$ & $9.90 \pm 0.50$ & $9.80 \pm 3.11$ & $50.5 \pm 26.9$ & $86.9 \pm 47.5$ \\
\hline & & DOPC & $9.06 \pm 0.42$ & $9.91 \pm 0.52$ & $6.86 \pm 0.54$ & $72.6 \pm 8.7$ & $110.3 \pm 50.3$ \\
\hline & & DOPC & $9.13 \pm 0.43$ & $10.07 \pm 0.53$ & $6.82 \pm 0.48$ & $73.4 \pm 7.3$ & $79.9 \pm 32.9$ \\
\hline & & DOPC & $9.13 \pm 0.43$ & $10.08 \pm 0.52$ & $6.72 \pm 0.64$ & $71.9 \pm 6.8$ & $65.8 \pm 31.6$ \\
\hline \multirow[t]{5}{*}{3} & 9 & SM & $9.07 \pm 0.43$ & $9.96 \pm 0.54$ & $6.81 \pm 0.54$ & $73.7 \pm 7.3$ & $74.5 \pm 51.8$ \\
\hline & & DOPC & $9.00 \pm 0.44$ & $9.92 \pm 0.54$ & $6.91 \pm 0.64$ & $73.1 \pm 7.6$ & $74.7 \pm 61.0$ \\
\hline & & DOPC & $9.07 \pm 0.45$ & $10.00 \pm 0.54$ & $6.92 \pm 0.72$ & $72.0 \pm 7.2$ & $74.9 \pm 26.1$ \\
\hline & & DOPC & $9.05 \pm 0.41$ & $9.93 \pm 0.50$ & $6.93 \pm 0.45$ & $72.0 \pm 7.0$ & $96.4 \pm 39.5$ \\
\hline & & DOPC & $9.11 \pm 0.41$ & $10.03 \pm 0.51$ & $6.71 \pm 0.58$ & $73.6 \pm 6.6$ & $80.5 \pm 31.3$ \\
\hline
\end{tabular}




\begin{tabular}{cccccc} 
DOPC & $9.13 \pm 0.45$ & $10.03 \pm 0.55$ & $6.97 \pm 0.48$ & $71.5 \pm 7.1$ & $65.7 \pm 35.4$ \\
SM & $9.01 \pm 0.48$ & $9.91 \pm 0.58$ & $6.89 \pm 1.25$ & $71.6 \pm 9.6$ & $42.3 \pm 28.0$ \\
PSM & $8.95 \pm 0.42$ & $9.82 \pm 0.50$ & $6.99 \pm 0.55$ & $72.7 \pm 6.8$ & $53.1 \pm 27.8$ \\
DOPC & $9.10 \pm 0.42$ & $10.00 \pm 0.51$ & $6.77 \pm 0.63$ & $71.6 \pm 6.9$ & $84.1 \pm 34.3$ \\
\hline
\end{tabular}

Comment on Tables 2-4: The complexes established between the tweezers (CLR01 and CLR05) and a lipid significantly differ from those that PC establishes with the lipids (see also Figure S4c) regarding the orientation of the lipid's head-group with respect to the central unit of the tweezers and clip as measured by the angle $\Phi$. While complexes between CLR01/CLR05 and DOPC/SM featured, in general, $\Phi$ values of around $10^{\circ}-30^{\circ}$ with an overall standard deviation of about $15^{\circ}$, the respective $\mathbf{P C}$ complexes showed much larger $\Phi$ values (mostly in the $60^{\circ}-90^{\circ}$ range) and larger standard deviations. We note that, although the tweezer's complexes with SM are more stable than with DOPC, the number of binding events to DOPC is higher due to the larger amount of these lipids in the mixed bilayer. 


\section{Supplementary Table 5.}

Quantification of cryo-TEM images of CLR01 treated HCMV virions. Quantified from at least three individual experiments via blind assignment. n: number of virions

\begin{tabular}{c|c|c|c}
\hline sample & $\mathbf{n}$ & distorted envelope & intact envelope \\
\hline CLR01 & 39 & $33(84.6 \%)$ & $6(15.4 \%)$ \\
medium & 32 & $7(21.9 \%)$ & $25(78.1 \%)$ \\
\hline
\end{tabular}




\section{Supplementary References}

(1) Zwanzig, R. W. High-Temperature Equation of State by a Perturbation Method. I. Nonpolar Gases. J. Chem. Phys. 1954, 22 (8), 1420-1426. https://doi.org/10.1063/1.1740409.

(2) Comer, J.; Gumbart, J. C.; Hénin, J.; Lelièvre, T.; Pohorille, A.; Chipot, C. The Adaptive Biasing Force Method: Everything You Always Wanted To Know but Were Afraid To Ask. J. Phys. Chem. B 2015, 119 (3), 1129-1151. https://doi.org/10.1021/jp506633n.

(3) Phillips, J. C.; Braun, R.; Wang, W.; Gumbart, J.; Tajkhorshid, E.; Villa, E.; Chipot, C.; Skeel, R. D.; Kalé, L.; Schulten, K. Scalable Molecular Dynamics with NAMD. Journal of Computational Chemistry. Wiley Subscription Services, Inc., A Wiley Company December 2005, pp 1781-1802. https://doi.org/10.1002/jcc.20289.

(4) Vanommeslaeghe, K.; MacKerell, A. D. CHARMM Additive and Polarizable Force Fields for Biophysics and Computer-Aided Drug Design. Biochim. Biophys. Acta, Gen. Subj. 2015, 1850 (5), 861-871. https://doi.org/10.1016/j.bbagen.2014.08.004.

(5) Zoete, V.; Cuendet, M. A.; Grosdidier, A.; Michielin, O. SwissParam: A Fast Force Field Generation Tool for Small Organic Molecules. J. Comput. Chem. 2011, 32 (11), 2359-2368. https://doi.org/10.1002/jcc.21816.

(6) Sugita, Y.; Okamoto, Y. Replica-Exchange Molecular Dynamics Method for Protein Folding. Chem. Phys. Lett. 1999, 314 (1-2), 141-151. https://doi.org/10.1016/S00092614(99)01123-9.

(7) Okabe, T.; Kawata, M.; Okamoto, Y.; Mikami, M. Replica-Exchange Monte Carlo Method for the Isobaric-Isothermal Ensemble. Chem. Phys. Lett. 2001, 335 (5-6), 435-439. https://doi.org/10.1016/S0009-2614(01)00055-0.

(8) Hess, B.; Kutzner, C.; van der Spoel, D.; Lindahl, E. GROMACS 4: Algorithms for Highly Efficient, Load-Balanced, and Scalable Molecular Simulation. J. Chem. Theory Comput. 2008, 4 (3), 435-447. https://doi.org/10.1021/ct700301q.

(9) Bjelkmar, P.; Larsson, P.; Cuendet, M. A.; Hess, B.; Lindahl, E. Implementation of the CHARMM Force Field in GROMACS: Analysis of Protein Stability Effects from Correction Maps, Virtual Interaction Sites, and Water Models. J. Chem. Theory Comput. 2010, 6 (2), 459-466. https://doi.org/10.1021/ct900549r.

(10) Mackerell, A. D.; Feig, M.; Brooks, C. L. Extending the Treatment of Backbone Energetics in Protein Force Fields: Limitations of Gas-Phase Quantum Mechanics in Reproducing Protein Conformational Distributions in Molecular Dynamics Simulations. J. Comput. Chem. 2004, 25 (11), 1400-1415. https://doi.org/10.1002/jcc.20065.

(11) Lump, E.; Castellano, L. M.; Meier, C.; Seeliger, J.; Erwin, N.; Sperlich, B.; Stürzel, C. M.; Usmani, S.; Hammond, R. M.; Von Einem, J.; Gerold, G.; Kreppel, F.; BravoRodriguez, K.; Pietschmann, T.; Holmes, V. M.; Palesch, D.; Zirafi, O.; Weissman, D.; Sowislok, A.; Wettig, B.; Heid, C.; Kirchhoff, F.; Weil, T.; Klärner, F. G.; Schrader, T.; Bitan, G.; Sanchez-Garcia, E.; Winter, R.; Shorter, J.; Munch, J. A Molecular Tweezer Antagonizes Seminal Amyloids and HIV Infection. Elife 2015, 4 (AUGUST2015), 1-33. https://doi.org/10.7554/eLife.05397.

(12) MacKerell, A. D. J.; Bashford, D.; Bellott, M.; Dunbrack, R. L.; Evanseck, J. D.; Field, M. J.; Fischer, S.; Gao, J.; Guo, H.; Ha, S.; Joseph-McCarthy, D.; Kuchnir, L.; Kuczera, K.; Lau, F. T.; Mattos, C.; Michnick, S.; Ngo, T.; Nguyen, D. T.; Prodhom, B.; Reiher, W. E.; Roux, B.; Schlenkrich, M.; Smith, J. C.; Stote, R.; Straub, J.; Watanabe, M.; Wiórkiewicz-Kuczera, J.; Yin, D.; Karplus, M. All-Atom Empirical Potential for Molecular Modeling and Dynamics Studies of Proteins. J. Phys. Chem. B 1998, 102 (18), 3586-3616. https://doi.org/10.1021/jp973084f. 
(13) Jorgensen, W. L.; Chandrasekhar, J.; Madura, J. D.; Impey, R. W.; Klein, M. L. Comparison of Simple Potential Functions for Simulating Liquid Water. J. Chem. Phys. 1983, 79 (2), 926-935. https://doi.org/10.1063/1.445869.

(14) Bier, D.; Rose, R.; Bravo-Rodriguez, K.; Bartel, M.; Ramirez-Anguita, J. M.; Dutt, S.; Wilch, C.; Klärner, F.-G.; Sanchez-Garcia, E.; Schrader, T.; Ottmann, C. Molecular Tweezers Modulate 14-3-3 Protein-Protein Interactions. Nat. Chem. 2013, 5 (3), 234239. https://doi.org/10.1038/nchem.1570.

(15) Dutt, S.; Wilch, C.; Gersthagen, T.; Talbiersky, P.; Bravo-Rodriguez, K.; Hanni, M.; Sánchez-García, E.; Ochsenfeld, C.; Klärner, F. G.; Schrader, T. Molecular Tweezers with Varying Anions: A Comparative Study. J. Org. Chem. 2013, 78 (13), 6721-6734. https://doi.org/10.1021/jo4009673.

(16) Nanga, R. P. R.; Brender, J. R.; Vivekanandan, S.; Popovych, N.; Ramamoorthy, A. NMR Structure in a Membrane Environment Reveals Putative Amyloidogenic Regions of the SEVI Precursor Peptide PAP248-286. J. Am. Chem. Soc. 2009, 131 (49), 17972-17979. https://doi.org/10.1021/ja908170s.

(17) Bennett, C. H. Efficient Estimation of Free Energy Differences from Monte Carlo Data. J. Comput. Phys. 1976, 22 (2), 245-268. https://doi.org/10.1016/00219991(76)90078-4.

(18) Darve, E.; Rodríguez-Gómez, D.; Pohorille, A. Adaptive Biasing Force Method for Scalar and Vector Free Energy Calculations. J. Chem. Phys. 2008, 128 (14), 144120. https://doi.org/10.1063/1.2829861.

(19) Jo, S.; Kim, T.; Iyer, V. G.; Im, W. CHARMM-GUI: A Web-Based Graphical User Interface for CHARMM. J. Comput. Chem. 2008, 29 (11), 1859-1865. https://doi.org/10.1002/jcc.20945.

(20) Wu, E. L.; Cheng, X.; Jo, S.; Rui, H.; Song, K. C.; Dávila-Contreras, E. M.; Qi, Y.; Lee, J.; Monje-Galvan, V.; Venable, R. M.; Klauda, J. B.; Im, W. CHARMM-GUI Membrane Builder toward Realistic Biological Membrane Simulations. J. Comput. Chem. 2014, 35 (27), 1997-2004. https://doi.org/10.1002/jcc.23702.

(21) Grubmüller, H.; Heymann, B.; Tavan, P. Ligand Binding: Molecular Mechanics Calculation of the Streptavidin-Biotin Rupture Force. Science (80-. ). 1996, 271 (5251), 997-999. https://doi.org/10.1126/science.271.5251.997.

(22) Park, S.; Khalili-Araghi, F.; Tajkhorshid, E.; Schulten, K. Free Energy Calculation from Steered Molecular Dynamics Simulations Using Jarzynski's Equality. J. Chem. Phys. 2003, 119 (6), 3559-3566. https://doi.org/10.1063/1.1590311.

(23) Lee, C.; Yang, W.; Parr, R. G. Development of the Colle-Salvetti Correlation-Energy Formula into a Functional of the Electron Density. Phys. Rev. B 1988, 37 (2), 785-789. https://doi.org/10.1103/PhysRevB.37.785.

(24) Ahlrichs, R.; Bär, M.; Häser, M.; Horn, H.; Kölmel, C. Electronic Structure Calculations on Workstation Computers: The Program System Turbomole. Chem. Phys. Lett. 1989, 162 (3), 165-169. https://doi.org/10.1016/0009-2614(89)85118-8.

(25) Grimme, S.; Ehrlich, S.; Goerigk, L. Effect of the Damping Function in Dispersion Corrected Density Functional Theory. J. Comput. Chem. 2011, 32 (7), 1456-1465. https://doi.org/10.1002/jcc.21759.

(26) Metz, S.; Kästner, J.; Sokol, A. A.; Keal, T. W.; Sherwood, P. ChemShell-a Modular Software Package for QM/MM Simulations. Wiley Interdiscip. Rev. Comput. Mol. Sci. 2014, 4 (2), 101-110. https://doi.org/10.1002/wcms.1163.

(27) Bakowies, D.; Thiel, W. Hybrid Models for Combined Quantum Mechanical and Molecular Mechanical Approaches. J. Phys. Chem. 1996, 100 (25), 10580-10594. https://doi.org/10.1021/jp9536514.

(28) de Vries, A. H.; Sherwood, P.; Collins, S. J.; Rigby, A. M.; Rigutto, M.; Kramer, G. J. Zeolite Structure and Reactivity by Combined Quantum-Chemical-Classical 
Calculations. J. Phys. Chem. B 2002, 103 (29), 6133-6141.

https://doi.org/10.1021/jp9913012.

(29) Antes, I.; Thiel, W. On the Treatment of Link Atoms in Hybrid Methods. In Combined Quantum Mechanical and Molecular Mechanical Methods; ACS Symposium Series; American Chemical Society, 2009; Vol. 712, pp 50-65. https://doi.org/10.1021/bk1998-0712.ch004.

(30) Todorov, I. T.; Smith, W. DL_POLY_3: The CCP5 National UK Code for MolecularDynamics Simulations. Philosophical Transactions: Mathematical, Physical and Engineering Sciences. Royal Society 2004, pp 1835-1852. https://doi.org/10.2307/4142464.

(31) Talbiersky, P.; Bastkowski, F.; Klärner, F. G.; Schrader, T. Molecular Clip and Tweezer Introduce New Mechanisms of Enzyme Inhibition. J. Am. Chem. Soc. 2008, 130 (30), 9824-9828. https://doi.org/10.1021/ja801441j.

(32) Fokkens, M.; Jasper, C.; Schrader, T.; Koziol, F.; Ochsenfeld, C.; Polkowska, J.; Lobert, M.; Kahlert, B.; Klärner, F. G. Selective Complexation of N-Alkylpyridinium Salts: Binding of NAD + in Water. Chem. - A Eur. J. 2005, 11 (2), 477-494. https://doi.org/10.1002/chem.200400603.

(33) Schrader, T.; Fokkens, M.; Klärner, F.-G.; Polkowska, J.; Bastkowski, F. Inclusion of Thiamine Diphosphate and S-Adenosylmethionine at Their Chemically Active Sites. $J$. Org. Chem. 2005, 70 (25), 10227-10237. https://doi.org/10.1021/jo0511896.

(34) Arnold, F.; Schnell, J.; Zirafi, O.; Sturzel, C.; Meier, C.; Weil, T.; Standker, L.; Forssmann, W.-G.; Roan, N. R.; Greene, W. C.; Kirchhoff, F.; Munch, J. Naturally Occurring Fragments from Two Distinct Regions of the Prostatic Acid Phosphatase Form Amyloidogenic Enhancers of HIV Infection. J. Virol. 2012, 86 (2), 1244-1249. https://doi.org/10.1128/jvi.06121-11.

(35) Münch, J.; Rücker, E.; Ständker, L.; Adermann, K.; Goffinet, C.; Schindler, M.; Wildum, S.; Chinnadurai, R.; Rajan, D.; Specht, A.; Giménez-Gallego, G.; Sánchez, P. C.; Fowler, D. M.; Koulov, A.; Kelly, J. W.; Mothes, W.; Grivel, J. C.; Margolis, L.; Keppler, O. T.; Forssmann, W. G.; Kirchhoff, F. Semen-Derived Amyloid Fibrils Drastically Enhance HIV Infection. Cell 2007, 131 (6), 1059-1071. https://doi.org/10.1016/j.cell.2007.10.014.

(36) Roan, N. R.; Müller, J. A.; Liu, H.; Chu, S.; Arnold, F.; Stürzel, C. M.; Walther, P.; Dong, M.; Witkowska, H. E.; Kirchhoff, F.; Münch, J.; Greene, W. C. Peptides Released by Physiological Cleavage of Semen Coagulum Proteins Form Amyloids That Enhance HIV Infection. Cell Host Microbe 2011, 10 (6), 541-550. https://doi.org/10.1016/j.chom.2011.10.010.

(37) Müller, J. A.; Harms, M.; Schubert, A.; Mayer, B.; Jansen, S.; Herbeuval, J. P.; Michel, D.; Mertens, T.; Vapalahti, O.; Schmidt-Chanasit, J.; Münch, J. Development of a High-Throughput Colorimetric Zika Virus Infection Assay. Med. Microbiol. Immunol. 2017, 206 (2), 175-185. https://doi.org/10.1007/s00430-017-0493-2.

(38) Reed, L. J.; Muench, H. A Simple Method of Estimating Fifty per Cent Endpoints. Am. J. Epidemiol. 1938, 27 (3), 493-497. https://doi.org/10.1093/oxfordjournals.aje.a118408.

(39) Schandock, F.; Riber, C. F.; Röcker, A.; Müller, J. A.; Harms, M.; Gajda, P.; Zuwala, K.; Andersen, A. H. F.; Løvschall, K. B.; Tolstrup, M.; Kreppel, F.; Münch, J.; Zelikin, A. N. Macromolecular Antiviral Agents against Zika, Ebola, SARS, and Other Pathogenic Viruses. Adv. Healthc. Mater. 2017, 6 (23), 1700748. https://doi.org/10.1002/adhm.201700748.

(40) Röcker, A. E.; Müller, J. A.; Dietzel, E.; Harms, M.; Krüger, F.; Heid, C.; Sowislok, A.; Riber, C. F.; Kupke, A.; Lippold, S.; von Einem, J.; Beer, J.; Knöll, B.; Becker, S.; Schmidt-Chanasit, J.; Otto, M.; Vapalahti, O.; Zelikin, A. N.; Bitan, G.; Schrader, T.; 
Münch, J. The Molecular Tweezer CLR01 Inhibits Ebola and Zika Virus Infection. Antiviral Res. 2018, 152, 26-35. https://doi.org/10.1016/j.antiviral.2018.02.003.

(41) Sparrer, K. M. J.; Gableske, S.; Zurenski, M. A.; Parker, Z. M.; Full, F.; Baumgart, G. J.; Kato, J.; Pacheco-Rodriguez, G.; Liang, C.; Pornillos, O.; Moss, J.; Vaughan, M.; Gack, M. U. TRIM23 Mediates Virus-Induced Autophagy via Activation of TBK1. Nat. Microbiol. 2017, 2 (11), 1543-1557. https://doi.org/10.1038/s41564-017-0017-2.

(42) Runge, S.; Sparrer, K. M. J.; Lässig, C.; Hembach, K.; Baum, A.; García-Sastre, A.; Söding, J.; Conzelmann, K. K.; Hopfner, K. P. In Vivo Ligands of MDA5 and RIG-I in Measles Virus-Infected Cells. PLoS Pathog. 2014, 10 (4), e1004081.

https://doi.org/10.1371/journal.ppat.1004081. 